\title{
A plasticity model for spudcan foundations in soft clay
}

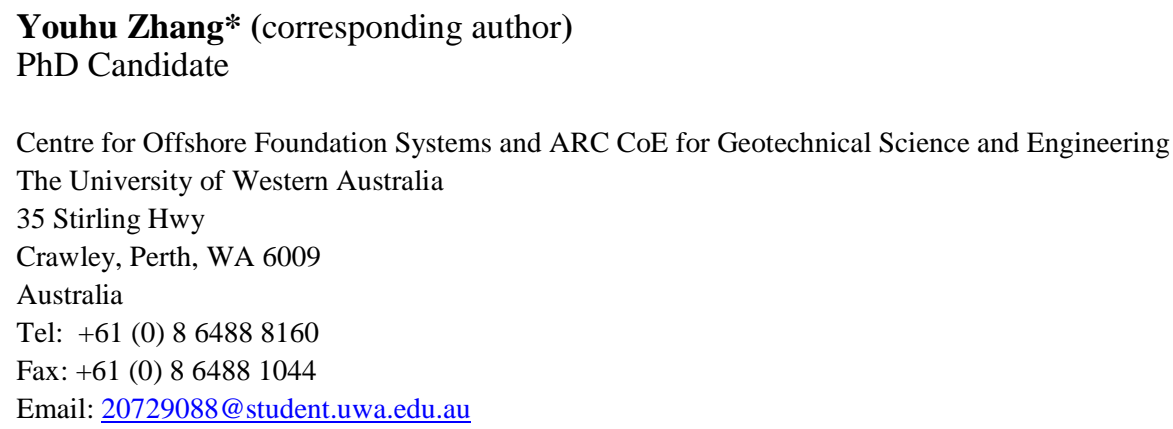

\section{Mark J. Cassidy}

\section{Director}

Lloyd's Register Foundation Chair of Offshore Foundations

Centre for Offshore Foundation Systems, The UWA Oceans Institute and ARC CoE for Geotechnical Science and Engineering

The University of Western Australia

35 Stirling Hwy

Crawley, Perth, WA 6009

Australia

Tel: $+61(0) 864883732$

Fax: +61 (0) 864881044

Email: mark.cassidy@uwa.edu.au

\section{Britta Bienen}

Associate Professor

ARC Postdoctoral Fellow

Centre for Offshore Foundation Systems and ARC CoE for Geotechnical Science and Engineering The University of Western Australia

35 Stirling Hwy

Crawley, Perth, WA 6009

Australia

Tel: +61 (0) 864884246

Fax: +61 (0) 864881044

Email: britta.bienen@uwa.edu.au

Manuscript submitted to Canadian Geotechnical Journal on July 20, 2013

No. of words: 6500 (without references)

No. of tables: 4

No. of figures: 22

Keywords: spudcan, combined loading, yield surface, geotechnical centrifuge, soft clay, force resultant modelling 


\section{A plasticity model for spudcan foundations in soft clay}

\section{ABSTRACT}

3 A plasticity model for predicting the load-displacement behaviour of a typical spudcan 4 foundation for offshore jack-up platforms under combined vertical, horizontal and moment 5 loading in soft clay is presented. Results from geotechnical centrifuge experiments of a 6 spudcan embedded vertically to $0.7,1.0$ and 1.45 footing diameters are described.

7 Augmented with finite element results these centrifuge experiments are used to evaluate the 8 plasticity model components. As a result of soil backflow on top of the spudcan, enhanced combined bearing capacity was measured and this is reflected in increased yield surface size. A tensile vertical load capacity is also incorporated. The excellent predictive capabilities of the model are demonstrated by retrospectively simulating a selection of centrifuge tests.

\section{INTRODUCTION}

Mobile jack-up platforms are widely used for performing drilling activities in the offshore industry. A modern jack-up platform typically consists of three independent legs. Under each leg, a circular saucer shaped foundation known as spudcan (Figure 1) is embedded in the seabed, supporting the superstructure. Due to the environmental loading from wind, wave and current, spudcan foundations are subjected to complex combined vertical $(V)$, horizontal $(H)$ and moment $(M)$ loading (see Figure 1 for the sign conventions for positive loads and conjugate displacements adopted in this paper). A jack-up is deployed multiple times throughout its life. Before each installation at a new site, a site specific assessment must demonstrate its stability in large storms (SNAME 2008; ISO 2012). This requires understanding of the bearing capacity of each spudcan as well as their interaction with the jack-up structure. 
3 Traditionally, spudcan footings have been simply treated as pin joints or a set of springs in

4 the jack-up structural analysis, with foundation 'failure' under the storm evaluated separately

5 using capacity surfaces written in terms of the VHM loads on the spudcan (see SNAME 2008,

6 ISO 2012 for example). A significant improvement has been the development of force

7 resultant foundation models that encapsulate the behaviour of the spudcan and surrounding

Figure 1. A typical spudcan foundation under combined $V H M$ loading and corresponding displacements soil within a plasticity framework (Schotman 1989; Nova and Montrasio 1991; Dean et al. 1997; Gottardi et al. 1999; Martin and Houlsby 2000, 2001; Cassidy et al. 2002a; Houlsby and Cassidy 2002; Bienen et al. 2006). These can be readily incorporated into a finite element structural analysis program as 'macro elements' as they are written directly in terms of force resultants and displacements about the spudcan's load reference point (LRP, Figure 1). This avoids any complex discretization of the soil. Such integrated foundation-structure analyses of mobile jack-up platforms can be found, amongst others, in Thompson (1996), Williams et al. (1998), Martin and Houlsby (1999), Cassidy et al. (2001, 2002b), Houlsby and Cassidy (2002), Bienen and Cassidy (2006, 2009) and Vlahos et al. (2011).

The majority of force-resultant models have been based on single surface displacementhardening plasticity theory. These have four components:

(i) a yield surface written directly in VHM load space;

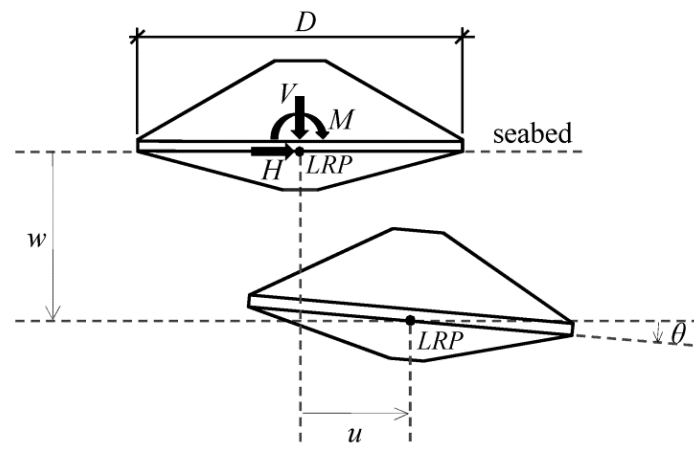


(ii) a hardening law that establishes the yield surface size as a function of the plastic vertical footing displacement $\left(w_{\mathrm{p}}\right)$

(iii) an elastic matrix for describing any increment of load within the yield surface; and

(iv) a flow rule to describe the elasto-plastic displacements during incremental expansion and contraction of the yield surface.

The current state-of-the-art model for predicting spudcan load-displacement behaviour in clay was developed by Martin and Houlsby $(2000,2001)$ and based on a series of $1 \mathrm{~g}$ laboratory tests in over-consolidated clay. No significant backflow was present in the tests even at relative large embedment depth of 1.6 footing diameters. Therefore, the model's yield surface only accounts for the contribution from the underside of the spudcan. However, in soft clays and at realistic field stress conditions, soil has been shown to encase the spudcan by flowing around the penetrating footing (Hossain et al. 2005; Hossain and Randolph 2009a) and this process has been codfied in the new ISO industry guidelines (ISO 2012). The backflow soil, though remoulded during the installation process, potentially provides additional bearing capacity, especially for moment and horizontal loading. Furthermore, the backflow acts as a 'seal' on top of the spudcan, allowing suction to be developed, as shown in the centrifuge tests of Cassidy et al. (2004), Purwana et al. (2005) and Gaudin et al. (2011). This may considerably change the foundation behaviour under combined loading at very low or even tensile vertical load. Experimental push-over tests of a scaled model jack-up in clay have shown that a spudcan can sustain significant horizontal and moment reactions even under tensile vertical load (Vlahos et al. 2008).

To assess these potential benefits, the finite element method has been recently used to define the combined bearing capacity surfaces of 'wished in place' spudcan foundations with 
9 The purpose of the research described in this paper was to i) experimentally measure the

complete backflow (Templeton et al. 2005; Templeton 2009; Zhang et al. 2011, 2012a) and enlarged surfaces primarily based on Templeton's work have been incorporated in the ISO guidelines (ISO 2012). Whilst the numerical studies confirmed an increase in combined loading capacity, there is a need to verify the magnitude of this increase experimentally. This is because soil undergoes significant displacement and remoulding during the spudcan installation. The effect of this was not considered in the numerical studies and the capacity is likely to have been overestimated.

combined bearing capacity of a buried spudcan in soft clay and to ii) develop a force resultant foundation model that is appropriate for spudcan foundations in soft clay. Solutions for the relevant elastic behaviour have already been published (Zhang et al. 2012b) and these are used here. Further, a method to predict the vertical capacity in soft clay has been proposed by Hossain and Randolph (2009a; 2009b) based on combined numerical and experimental investigations and this forms the basis of the hardening law. However, a dedicated geotechnical centrifuge test programme was required to investigate the remaining components of (a) the yield surface in VHM space at various depths of embedment and (b) an appropriate flow rule. The centrifuge experiments reveal that the backflow considerably increases the footing's combined bearing capacity as compared to previous $1 \mathrm{~g}$ experiments results without backflow. The magnitude is, however, less than that predicted by the wished in place numerical analyses and, concerningly, as is recommended by the ISO guidelines. 
2 The tests were performed with a combined VHM loading apparatus developed recently for the

3 geotechnical drum centrifuge at the University of Western Australia (UWA) (Zhang et al.

4 2013). The apparatus features independent displacement control of a model's in-plane

5 vertical, horizontal and rotational degrees-of-freedom. Therefore, any combination of

6 displacements can be prescribed to the model about its $L R P$. Figure 2 shows the assembly of

7 the VHM loading apparatus with the model spudcan and loading arm attached. For the

8 experiments described in this paper the model spudcan was $60 \mathrm{~mm}$ in diameter $(D)$,

9 corresponding to $12 \mathrm{~m}$ in prototype at the enhanced $200 \mathrm{~g}$ gravity level used in the tests. The

10 loading arm consisted of a strain-gauged inner arm (used to measure the $V, H$ and $M$ forces

11 acting solely on the spudcan and reported here at the $L R P$ ) and a stiff outer shield (that

12 isolated the combined loads on the loading arm). A more detailed description of the spudcan,

13 loading arm and test set-up are available in Zhang et al. (2013).

14

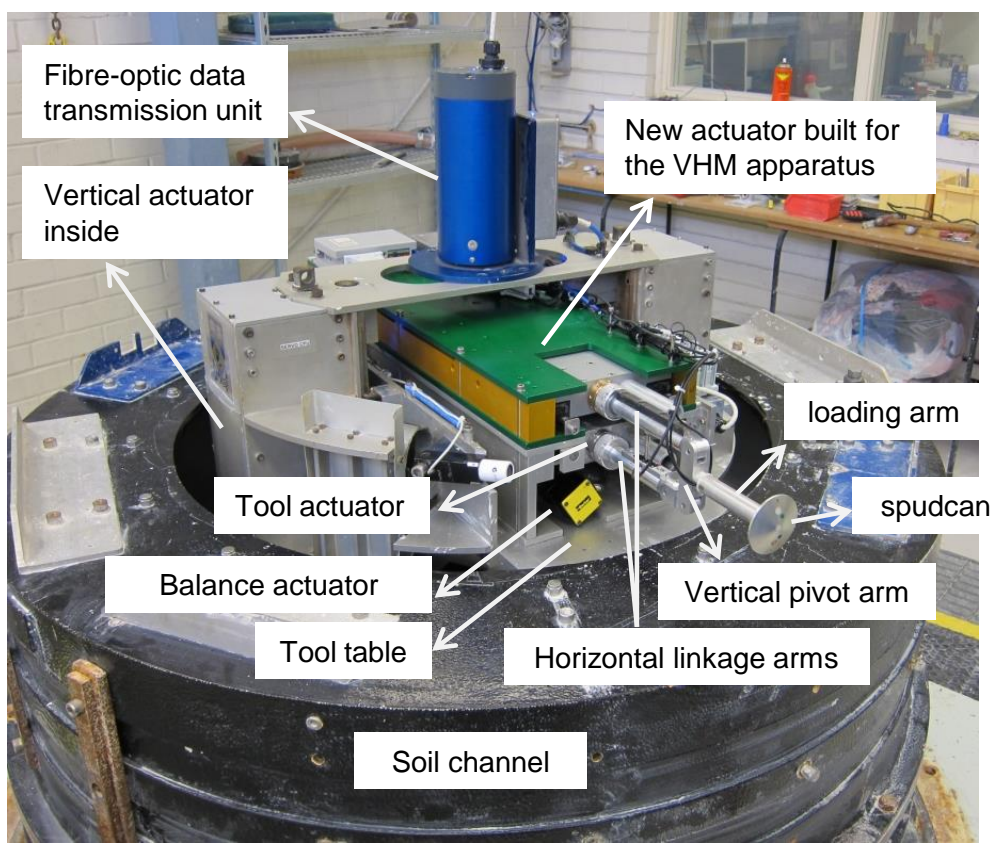


2 The tests were performed in normally consolidated (NC) UWA kaolin clay (with properties 3 provided by Stewart 1992). To prepare the soil sample, the kaolin powder was mixed at

$4120 \%$ water content (twice the liquid limit) under vacuum and consolidated under self-weight 5 in the centrifuge at $200 \mathrm{~g}$.

6

7 The soil was characterised by in flight miniature T-bar penetrometer tests (Stewart and 8 Randolph 1994). In each T-bar test, cycles of penetration and extraction over a depth of $920 \mathrm{~mm}$ (4 times the T-bar diameter) were performed until the penetration/extraction 10 resistance did not change with further cycles (i.e. fully remoulded). Such a cyclic event is 11 illustrated in Figure 3 for one test, whereas only the initial penetration is shown for the 12 remaining tests. The undrained shear strength $\left(s_{\mathrm{u}}\right)$ was derived using a typical T-bar factor of $13 N_{\text {T-bar }}=10.5$ (Einav and Randolph 2005; Dejong et al. 2011). The depth axis is shown in 14 prototype scale. A nonlinear expression of $s_{\mathrm{u}}=0.849 w+0.02 w^{2}$ provides a good fit to the 15 undrained shear strength profile. The slight nonlinearity is attributable to linearly increasing gravity field over the sample depth in the drum centrifuge. Previous studies (Stewart 1992;

17 Randolph and Hope 2004) have suggested an empirical normally consolidated strength ratio $s_{\mathrm{u}} / \sigma_{\mathrm{v} 0} 0^{\prime}=0.185$ for the UWA kaolin clay. In Figure 3, this empirical prediction is shown to 19 match the T-bar results well (note that the changing gravity field and variation of effective unit weight with depth were taken into account when calculating $\sigma_{\mathrm{v} 0}{ }^{\prime}$ ). 


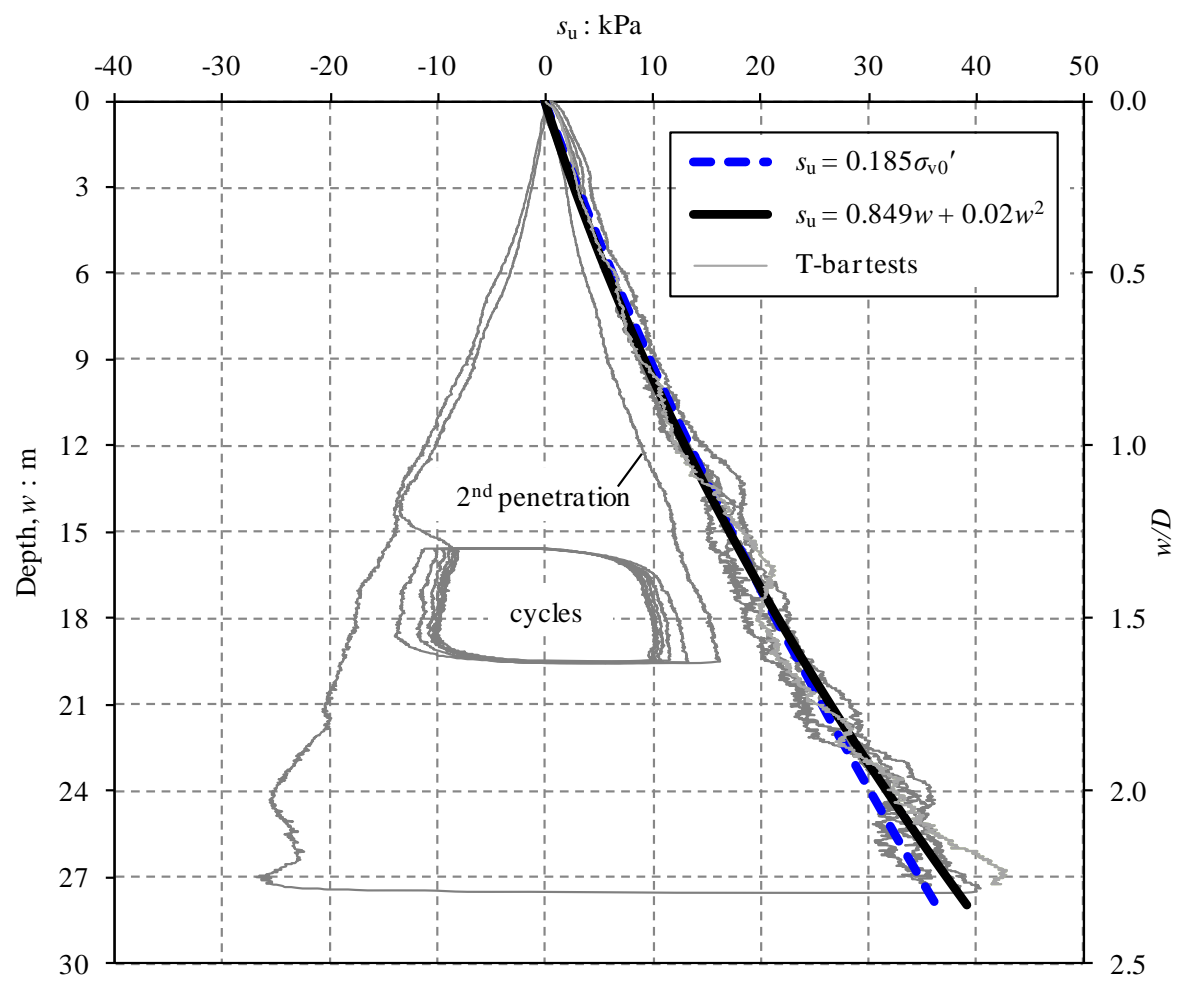

Figure 3. Undrained shear strength profile determined from T-bar tests

4 Figure 4 illustrates the soil strength degradation pattern during the cyclic T-bar events. The degradation factor is defined as the resistance (penetration/extraction) encountered by the T-

6 bar at the middle depth of the cycles normalised by the initial penetration resistance (taken as

7 cycle 0.5 , Randolph 2004). Good repeatability is found and the limiting degradation factor is 80.45 , indicating a sensitivity $\left(S_{\mathrm{t}}\right)$ of $1 / 0.45=2.2$. This is consistent with other cyclic T-bar 9 tests performed on UWA Kaolin clay (e.g. Hodder et al. 2010; Mana et al. 2012). 


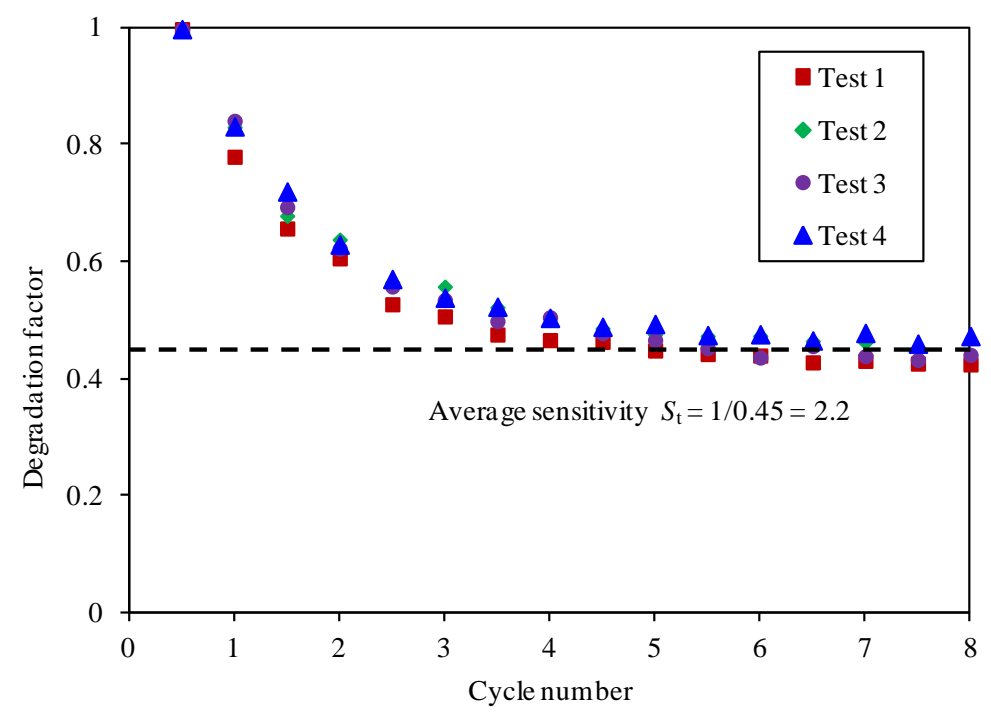

EXPERIMENTAL PROGRAMME

5 The experimental programme concentrates on swipe tests (e.g. Tan 1990; Gottardi et al 6 1999; Martin and Houlsby 2000) and radial displacement tests (e.g. Gottardi et al. 1999;

7 Byrne and Houlsby 2001; Bienen et al. 2006) to evaluate the yield surface and flow rule, 8 respectively, of the spudcan at three embedment depths, $0.7 \mathrm{D}, 1.0 \mathrm{D}$ and $1.45 \mathrm{D}$. In addition, 9 two pure vertical penetration-extraction tests were performed. Table 1 and Table 2 summarise 10 the swipe and radial displacement testing programmes respectively.

12 Swipe tests

13 In a usual swipe test, the footing is first penetrated to a prescribed vertical depth. This is 14 immediately followed by an excursion of translation $(u)$ or/and rotation $(\theta)$ while the vertical displacement is held constant. Commencing from the peak compressive vertical load, a path

16 on the VHM yield surface is tracked. By carrying out a systematic series of tests with 
4 To investigate the yield surface on the tensile side of vertical load, some swipe tests were This assumption is illustrated in Figure 5 Figure 5.

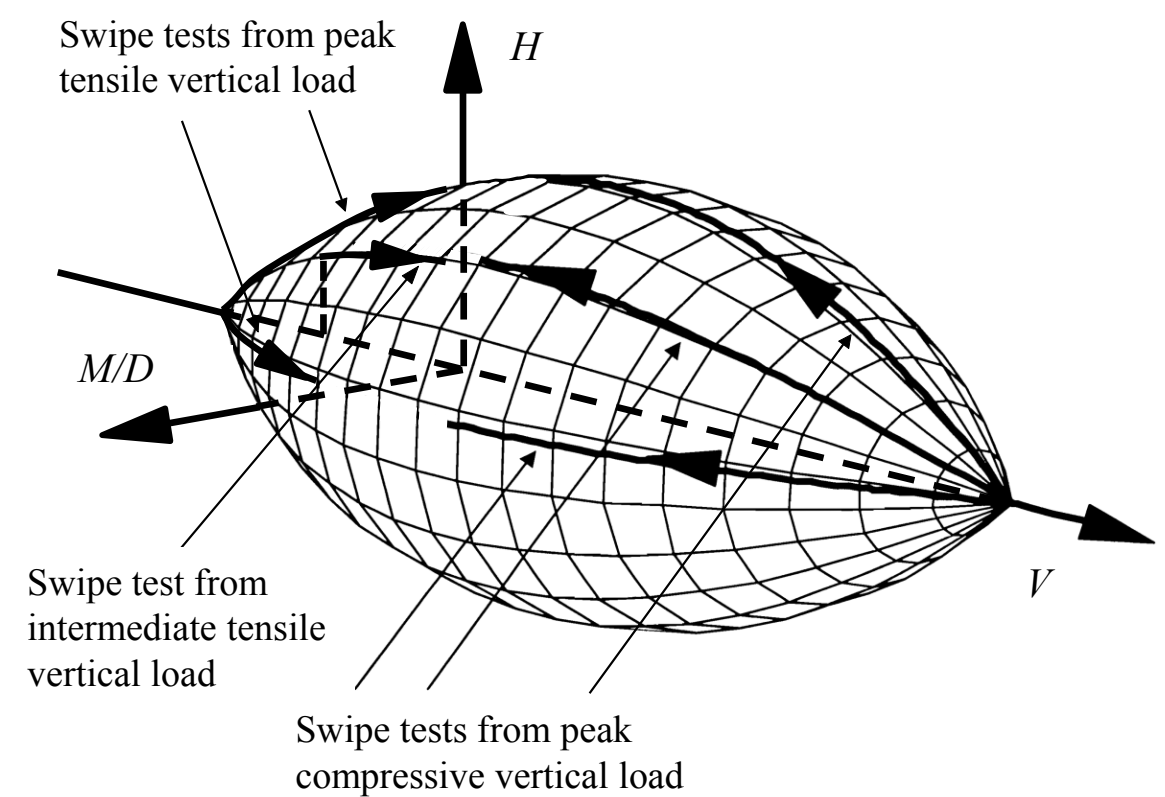


2 In the radial displacement tests the footing was subjected to a path of a fixed $u: w$ or $D \theta: w$

3 ratio (after being penetrated to an initial vertical embedment). Within the plasticity

4 framework, this represents continuous elasto-plastic expansion of the yield surface. The tests,

5 therefore, provide a basis for the development of the flow rule.

6

7 Two types of radial displacement tests were performed with slightly different procedures,

8 with the assumed load paths schematically illustrated in Figure 6 (noting that in a radial

9 displacement test the displacements are prescribed and the loads measured). The load paths

10 represented by solid lines in the figure will be achieved by the application of radial

11 displacements immediately after purely vertical penetration of the footing to a pre-selected

12 depth. Plasticity theory implies that the load path starts from pure vertical load and expands

13 the yield surface as the test proceeds. However, if the spudcan is unloaded elastically to

14 around zero vertical load following the initial pure vertical penetration before radial

15 displacements are applied, the load path will increase linearly to the yield surface

16 (corresponding to the maximum previously experienced $w_{\mathrm{p}}$ ) before expanding the yield

17 surface from that point on. These load paths are indicated in the figure by the dashed lines.

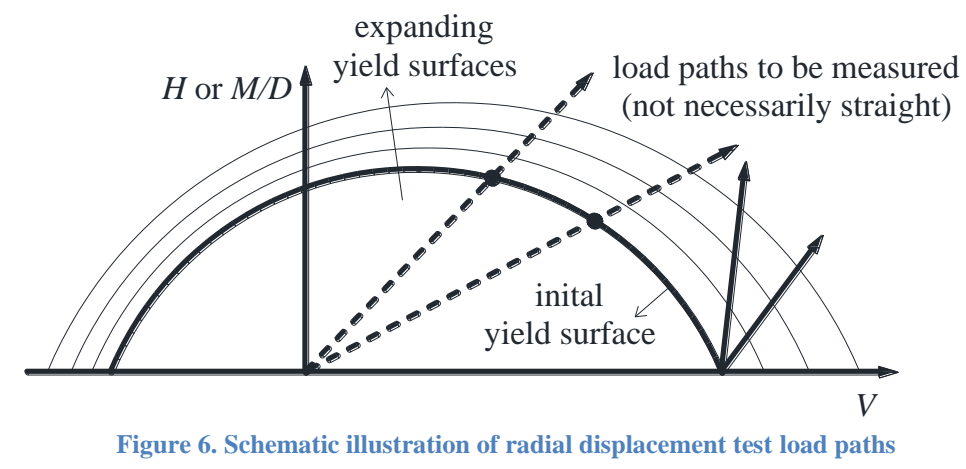

Each swipe or radial displacement test represented a vertical penetration test before the swipe or radial displacements were applied. In all tests, the pure vertical penetration/extraction of 
the spudcan was performed at a rate of $\dot{w}=0.2 \mathrm{~mm} / \mathrm{s}$. Assuming a coefficient of

9 Effect of soil consolidation in the centrifuge and Table 2. consolidation $\left(c_{\mathrm{v}}\right)$ of $2.6 \mathrm{~m}^{2} /$ year for the effective stress level of interest (Stewart 1992), the non-dimensional velocity $\dot{w} D / c_{\mathrm{v}}$ was 146.2 , which was larger than the threshold value of 10 30 and thus ensured undrained conditions (Finnie 1993; House et al. 2001; Chung et al. 2006; Cassidy 2012). For swipe tests and radial displacement tests, the maximum horizontal and rotational rates were limited to $0.4 \mathrm{~mm} / \mathrm{s}$ and $0.4 \%$ respectively, as detailed in Table 1

Since this paper is concerned with the effects of the backflow on the foundation behaviour, and it is well-know that the disturbed backflow will regain strength with time due to dissipation of excess pore pressure (see Purwana et al. 2005, Gan et al. 2012 for discussion relevant to jack-ups), it is therefore important to ensure that the properties of the backflow was properly modelled in the tests. In the centrifuge, the linear geometries are scaled down by $\mathrm{N}$, while the rate of consolidation is scaled up by $\mathrm{N}^{2}$ (Taylor, 1995), where $\mathrm{N}$ is the centrifugal acceleration as a ratio of $\mathrm{g}$. In the field, a full preload of a jack-up normally takes about 24-36 h (Purwana et al. 2005) and soil maintains undrained during the installation process. In the centrifuge, undrained penetration process was also ensured with the dimensionless group $\dot{w} D / c_{\mathrm{v}}$ held above the threshold between a partial drained and undrained penetration, as discussed above. However, the time in prototype used in penetration is longer. For the deepest penetration of $1.45 \mathrm{D}$ in the test programme, the total penetration time in prototype was 40 days. This give an opportunity of possible consolidation of the backflow material after passage of the spudcan. However, a quick estimation with the calculation theory shows minimal consolidation will occur. It should be further noted that the backflow 
1 soil in the vicinity of the spudcan, which is more important on the footing behaviour, will 2 have even less time to consolidate.

3

4 As described above, in the swipes or radial displacements tests, lateral and (or) rotational 5 movement were immediately applied after the vertical event (penetration, and unloading for 6 certain tests), this was to ensure that the backflow material does not have the chance to 7 consolidate.

8

9 From the above discussions, the test procedures taken in this program ensures that the

10 foundation behaviour measured in the centrifuge tests reflects the behaviour of the spudcan 11 immediate after preloading in the field. Although the regaining of the soil strength with time 12 is possible, it was considered conservative to neglect the time effects in design. 
Table 1. Summary of the swipe testing programme followed

\begin{tabular}{|c|c|c|c|c|c|c|c|}
\hline \multirow{2}{*}{$\begin{array}{l}\text { Test } \\
\text { depth }\end{array}$} & \multirow{2}{*}{ Type } & \multirow{2}{*}{$\begin{array}{l}\text { Test } \\
\text { Name }\end{array}$} & \multirow{2}{*}{$u / D \theta$} & \multicolumn{2}{|c|}{ Swipe movement } & \multicolumn{2}{|c|}{ Velocities } \\
\hline & & & & $\begin{array}{c}u \\
(\mathrm{~mm})\end{array}$ & $\begin{array}{c}\theta \\
\left({ }^{\circ}\right)\end{array}$ & $\begin{array}{c}\dot{u} \\
(\mathrm{~mm} / \mathrm{s})\end{array}$ & $\begin{array}{c}\dot{\theta} \\
(\% / s)\end{array}$ \\
\hline \multirow{7}{*}{$0.7 D$} & \multirow{5}{*}{$\begin{array}{l}\text { Swipes from peak } \\
\text { compressive load }\end{array}$} & PCS1 & $\infty$ & 12 & 0 & 0.4 & 0 \\
\hline & & $\mathrm{PCS} 2$ & 0.95 & 9 & 9 & 0.4 & 0.4 \\
\hline & & PCS3 & -0.095 & -0.9 & 9 & -0.04 & 0.4 \\
\hline & & PCS4 & -0.57 & -5.4 & 9 & -0.24 & 0.4 \\
\hline & & PCS5 & -1.15 & -9 & 7.5 & -0.4 & 0.33 \\
\hline & \multirow{2}{*}{$\begin{array}{c}\text { Swipes from } \\
\text { intermediate tensile } \\
\text { load }\end{array}$} & ITS1 & $\infty$ & 12 & 0 & 0.4 & 0 \\
\hline & & ITS2 & -0.095 & -0.9 & 9 & -0.04 & 0.4 \\
\hline \multirow{4}{*}{$1.0 D$} & \multirow{4}{*}{$\begin{array}{l}\text { Swipes from peak } \\
\text { compressive load }\end{array}$} & PCS6 & $\infty$ & 12 & 0 & 0.4 & 0 \\
\hline & & PCS7 & 0.95 & 9 & 9 & 0.4 & 0.4 \\
\hline & & PCS8 & -0.095 & -0.9 & 9 & -0.04 & 0.4 \\
\hline & & PCS9 & -0.57 & -5.4 & 9 & -0.24 & 0.4 \\
\hline \multirow{11}{*}{$1.45 D$} & \multirow{5}{*}{$\begin{array}{l}\text { Swipes from peak } \\
\text { compressive load }\end{array}$} & PCS10 & $\infty$ & 12 & 0 & 0.4 & 0 \\
\hline & & PCS11 & 0.95 & 9 & 9 & 0.4 & 0.4 \\
\hline & & PCS12 & -0.095 & -0.9 & 9 & -0.04 & 0.4 \\
\hline & & PCS13 & -0.57 & -5.4 & 9 & -0.24 & 0.4 \\
\hline & & PCS14 & -1.15 & -9 & 7.5 & -0.4 & 0.33 \\
\hline & \multirow{2}{*}{$\begin{array}{c}\text { Swipes from } \\
\text { intermediate tensile } \\
\text { load }\end{array}$} & ITS3 & $\infty$ & 12 & 0 & 0.4 & 0 \\
\hline & & ITS4 & -0.095 & -0.9 & 9 & -0.04 & 0.4 \\
\hline & \multirow{4}{*}{$\begin{array}{l}\text { Swipes from peak } \\
\text { tensile load }\end{array}$} & PTS1 & $\infty$ & 12 & 0 & 0.4 & 0 \\
\hline & & PTS2 & 0.95 & 9 & 9 & 0.4 & 0.4 \\
\hline & & PTS3 & -0.095 & -0.9 & 9 & -0.04 & 0.4 \\
\hline & & PTS4 & -0.57 & -5.4 & 9 & -0.24 & 0.4 \\
\hline
\end{tabular}


Table 2. Summary of the radial displacement testing programme followed

\begin{tabular}{|c|c|c|c|c|c|c|c|}
\hline $\begin{array}{l}\text { Test } \\
\text { depth }\end{array}$ & Type & $\begin{array}{l}\text { Test } \\
\text { Name }\end{array}$ & Radial ratio & $\begin{array}{r}\mathrm{R} \\
\text { mov }\end{array}$ & $\begin{array}{l}\text { al } \\
\text { nent }\end{array}$ & Velo & ities \\
\hline \multirow{6}{*}{$0.7 D$} & $u: w$ plane & & $\begin{array}{c}\tan ^{-1}(u / w) \\
\left({ }^{\circ}\right)\end{array}$ & $\begin{array}{c}u \\
(\mathrm{~mm})\end{array}$ & $\begin{array}{c}w \\
(\mathrm{~mm})\end{array}$ & $\begin{array}{c}\dot{u} \\
(\mathrm{~mm} / \mathrm{s})\end{array}$ & $\begin{array}{c}\dot{W} \\
(\mathrm{~mm} / \mathrm{s})\end{array}$ \\
\hline & \multirow{2}{*}{$\begin{array}{l}\text { Radial tests after } \\
\text { elastic unload }\end{array}$} & $\mathrm{R} 1$ & 45 & 9 & 9 & 0.2 & 0.2 \\
\hline & & R2 & 78.7 & 12 & 2.4 & 0.4 & 0.08 \\
\hline & $D \theta: w$ plane & & $\begin{array}{c}\tan ^{-1}(D \theta / w) \\
\left({ }^{\circ}\right)\end{array}$ & $\begin{array}{c}\theta \\
\left({ }^{\circ}\right) \\
\end{array}$ & $\begin{array}{c}w \\
(\mathrm{~mm})\end{array}$ & $\begin{array}{c}\dot{\theta} \\
(\% / s)\end{array}$ & $\begin{array}{c}\dot{W} \\
(\mathrm{~mm} / \mathrm{s})\end{array}$ \\
\hline & \multirow{2}{*}{$\begin{array}{l}\text { Radial tests after } \\
\text { elastic unload }\end{array}$} & R3 & 46.3 & 9 & 9 & 0.2 & 0.2 \\
\hline & & $\mathrm{R} 4$ & 79.2 & 9 & 1.8 & 0.4 & 0.08 \\
\hline \multirow{11}{*}{$1.45 D$} & $u: w$ plane & & $\begin{array}{c}\tan ^{-1}(u / w) \\
\left({ }^{\circ}\right)\end{array}$ & $\begin{array}{c}u \\
(\mathrm{~mm})\end{array}$ & $\begin{array}{c}w \\
(\mathrm{~mm})\end{array}$ & $\begin{array}{c}\dot{u} \\
(\mathrm{~mm} / \mathrm{s})\end{array}$ & $\begin{array}{c}\dot{W} \\
(\mathrm{~mm} / \mathrm{s})\end{array}$ \\
\hline & & R5 & 22.5 & 3.73 & 9 & 0.083 & 0.2 \\
\hline & immediately after & R6 & 45 & 9 & 9 & 0.2 & 0.2 \\
\hline & veriticai peritilation & R7 & 76.7 & 21.1 & 5 & 0.4 & 0.095 \\
\hline & Radial tests after & $\mathrm{R} 8$ & 45 & 9 & 9 & 0.2 & 0.2 \\
\hline & elastic unload & R9 & 78.7 & 12 & 2.4 & 0.4 & 0.08 \\
\hline & $D \theta: w$ plane & & $\begin{array}{c}\tan ^{-1}(D \theta / w) \\
\left({ }^{\circ}\right)\end{array}$ & $\begin{array}{c}\theta \\
\left({ }^{\circ}\right) \\
\end{array}$ & $\begin{array}{c}w \\
(\mathrm{~mm})\end{array}$ & $\begin{array}{c}\dot{\theta} \\
(\% / s)\end{array}$ & $\begin{array}{c}\dot{\dot{W}} \\
(\mathrm{~mm} / \mathrm{s})\end{array}$ \\
\hline & Radial test & R10 & 22.5 & 3.56 & 9 & 0.079 & 0.2 \\
\hline & vertical penetration & R11 & 81.8 & 10 & 1.52 & 0.4 & 0.061 \\
\hline & Radial tests after & $\mathrm{R} 12$ & 46.3 & 9 & 9 & 0.2 & 0.2 \\
\hline & elastic unload & R13 & 79.2 & 9 & 1.8 & 0.4 & 0.08 \\
\hline
\end{tabular}

\section{FORCE RESULTANT MODEL}

$4 \quad$ Hardening law

5 The model assumes that the yield surface expands with the plastic vertical displacement of

6 the spudcan $\left(w_{\mathrm{p}}\right)$. As the yield surface will be expressed as a function of the pure vertical

7 capacity, an accurate description of the vertical capacity of the spudcan at a given plastic

8 embedment depth is required.

9 
1 For an embedded spudcan buried in backflow soil, the total vertical capacity for the footing to

2

$3 V_{\text {total_C }}=V_{0}+F_{\mathrm{b}}$

4 where $V_{0}$ represents the compressive vertical bearing capacity provided by the soil and $F_{\mathrm{b}}$

5 represents the buoyancy force on the spudcan. $V_{0}$ and $F_{\mathrm{b}}$ are calculated as:

$6 \quad V_{0}=N_{\mathrm{c}} A s_{\mathrm{u} 0}$

$7 \quad F_{\mathrm{b}}=\gamma^{\prime} \mathrm{Vol}$ weight of the soil and $\mathrm{Vol}$ is the volume of soil displaced by the footing.

where $s_{\mathrm{u} 0}$ is the undrained shear strength at the current plastic embedment depth, $N_{\mathrm{c}}$ is the vertical bearing capacity factor, $A$ is the bearing area of the footing, $\gamma^{\prime}$ is the effective unit

The total capacity for the spudcan to resist external tensile load is

$V_{\text {total_T }}=V_{\mathrm{T}}-F_{\mathrm{b}}$

where $V_{\mathrm{T}}$ is tensile capacity provided by the soil cohesive strength. Its ratio to the corresponding compressive capacity $\left(V_{\mathrm{T}} / V_{0}\right)$ is denoted as $\chi$, which will be shown useful when defining the yield surface.

In all tests, backflow was observed immediately after the spudcan LRP (Figure 1) penetrated past the soil surface. This is a result of very low $s_{\mathrm{u}}(\sim$ zero) at the NC soil sample surface. Figure 7 shows (i) the penetration-extraction response of the two vertical tests and (ii) the initial penetration of all 11 swipes that were performed at a depth of around $1.45 D(\sim 87 \mathrm{~mm})$. The resistance $(V)$ is the measured vertical capacity corrected for the buoyancy and shaft effect (unequal areas below and above the spudcan due to existence of the shaft, similar to correction needed for a CPT test (Randolph et al. 2007)). Therefore, it represents the net 

extraction).

3

4 The pure vertical tests show that a peak tensile capacity of about $60 \%$ of the compressive capacity $(\chi \approx 0.6)$ is mobilised at an extraction of $\sim 10 \%$ of the spudcan diameter (i.e. $6 \mathrm{~mm}$ in model scale). Upon the vertical movement reversal, the load-displacement response is approximately linear, indicating elastic behaviour. However, once the net vertical load becomes tensile, the stiffness begins to degrade and reaches zero as the peak tensile load is mobilised. Clearly this mobilisation process is elasto-plastic. Based on the vertical tests, swipes (results of which will be presented later) commencing from the peak tensile vertical load were performed after an extraction of $6 \mathrm{~mm}$; whilst those commencing from 2 intermediate tensile vertical load (60-70\% of the peak) tests were performed following 2.5 3 mm of upward vertical movement.

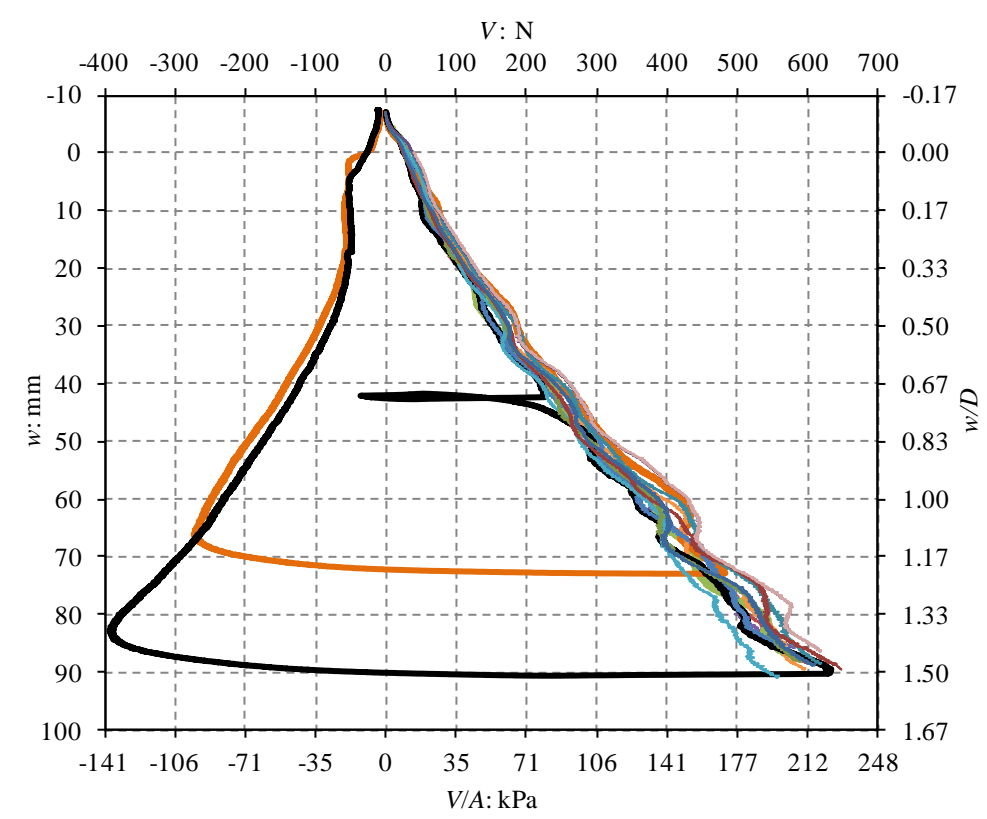


1 Figure 8 shows the derived vertical bearing capacity factor $\left(V / A s_{\mathrm{u} 0}\right)$ against the normalised 2 penetration depth $(w / D)$. As can be seen, it decreases rapidly at shallow depth and approaches 3 an average value of about 10 from approximately $0.5 D$, indicating formation of a continuous 4 flow-around soil mechanism. The large value at shallower depth is due to the high local soil 5 heterogeneity.

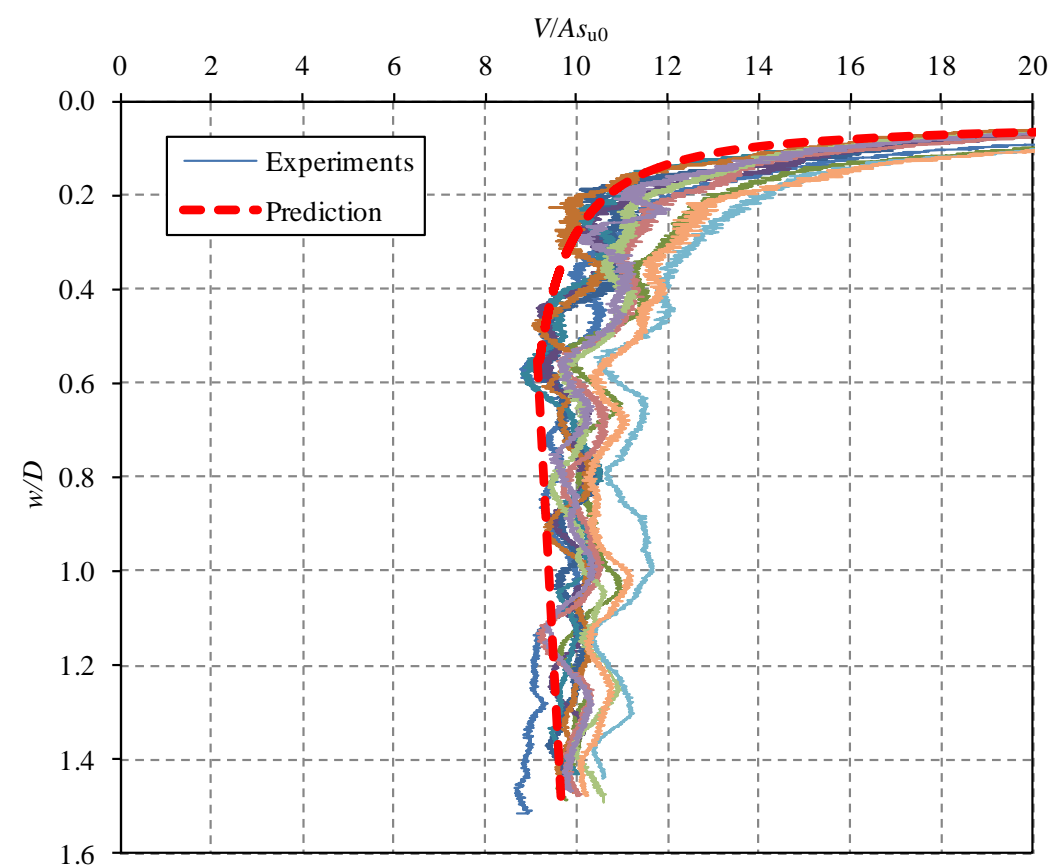

Figure 8. Vertical bearing capacity factor of the spudcan

Hossain and Randolph (2009a; 2009b) proposed a mechanism based method for predicting the vertical bearing capacity of spudcans in clayey soils. The method takes into account the different failure mechanisms at various stages of penetration and can consider the effect of penetration rate and soil sensitivity. If the penetration rate effect is neglected, the vertical bearing capacity factor is determined by

$$
N_{\text {cs }} \text { or } N_{\text {cd }}=\left(\delta_{\text {rem }}+\left(1-\delta_{\text {rem }}\right) e^{-3 \xi_{0} / \xi_{95}}\right) N_{\text {cs_ideal }} \text { or } N_{\text {cd_ideal }}
$$


where $N_{\mathrm{cs}}$ is the shallow bearing capacity factor for a general shear failure mechanism before backflow, $N_{\text {cd }}$ is the deep bearing capacity factor associated with a fully localised flowaround mechanism, $N_{\text {cs_ideal }}$ and $N_{\text {cd_ideal }}$ are corresponding shallow and deep bearing capacity factors respectively in an ideally non-strain softening soil (i.e. $S_{\mathrm{t}}=1$ ), $\delta_{\text {rem }}$ is the inverse of the soil sensitivity $S_{\mathrm{t}}, \xi_{\mathrm{b}}$ represents the average cumulative shear strain as experienced by the soil particles as they traverse the flow mechanism around the spudcan. Hossain and Randolph (2009b) suggested $\xi_{\mathrm{b}}$ to be $2.4 . \xi_{95}$ is the ductility parameter, which is equal to the cumulative strain required for $95 \%$ remoulding. Hossain and Randolph (2009a) recommend $N_{\text {cs_ideal }}$ to be determined by interpolation of results from wished in place numerical analyses with an open cavity and $N_{\text {cd_ideal }}$ to be calculated by

$N_{\text {cd_ideal }}=10\left(1+0.065 w_{\mathrm{p}} / D\right) \leq 11.3$

Between the onset of backflow to full localisation of the flow-around mechanism, a transitional depth of $0.5 D$ is assumed in this model. The transition reflects the physical response and avoids numerical difficulty through smoothing of the hardening law, which would otherwise exhibit a discontinuity. The bearing capacity in the transition zone is linearly interpolated. A small cavity depth of $0.05 D$ is predicted by the Hossain and Randolph (2009a) method for the NC soil profile (for numerical reasons, the undrained shear strength at the surface is assigned a value of $0.1 \mathrm{kPa}$ ). Figure 8 shows the model's prediction of the bearing capacity factor based on $S_{\mathrm{t}}=2.2$ (as derived for the experimental conditions from cyclic T-bar tests) and an assumed $\xi_{95}$ value of 30 . A reasonable match to the experiments is demonstrated. 
3 Figure 9Figure 9 presents the load paths of three similar swipes of $u / D \theta=0.95$ performed at

5 increasing embedment depth, the load paths tracked by the swipes increase in magnitude.

6 However, a similar shape is maintained. This illustrates nicely that the size of the yield

7 surface expands as the current plastic penetration $\left(w_{\mathrm{p}}\right)$ increases and that a simple hardening

8 law can be assumed.
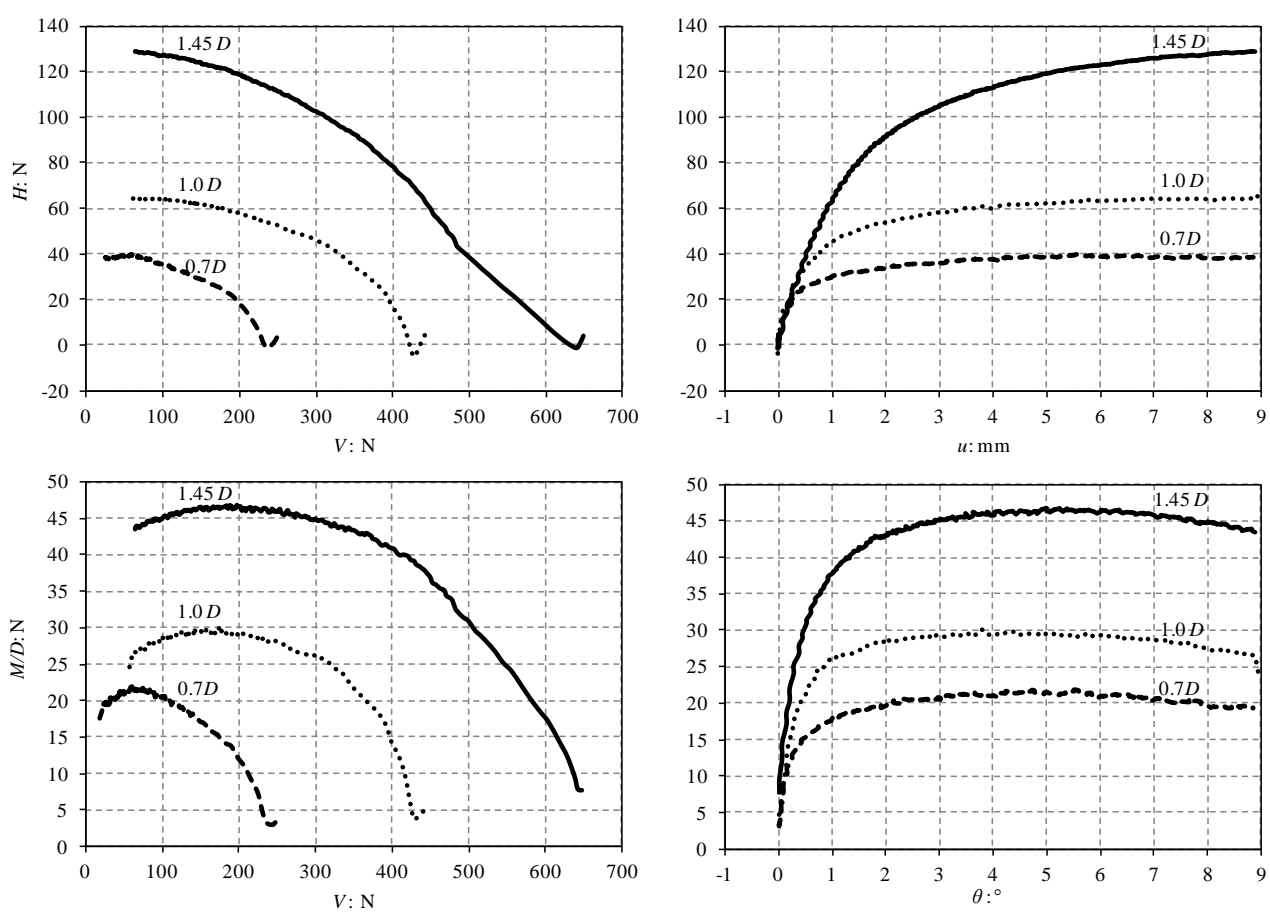

Figure 9. Load paths of similar swipe tests (PCS2, PCS7 and PCS11) performed at different embedment depths

12 Figure 10 presents the load paths of three pure translation swipes (i.e. $u / D \theta=\infty$; PCS10, 13 PTS1 and ITS3) that were performed from peak compressive, peak tensile and intermediate 14 tensile vertical loads respectively at an initial embedment depth of $1.45 D$ (note only the 15 limiting loads for test ITS3 are presented). The loads have been normalised by the 

maximum compressive vertical load prior to the extraction. The implication of this normalisation is that purely elastic behaviour during this initial pull out is assumed (or

4 alternatively the loss of $w_{\mathrm{p}}$ during the mobilisation of tensile load is neglected). This

5 assumption of the numerical model provides a simple and practical approach to evaluate and

6 eventually simulate the tensile swipe test results. As shown in Figure 10, the pair of swipes

7 performed from the peak compressive and peak tensile vertical loads track paths from two

8 ends of the $V H M$ surface at a similar $M / D H$ ratio. The limiting load combination of the

9 intermediate tensile swipe is also consistent with the yield surface established by the swipes performed from the peak vertical loads.
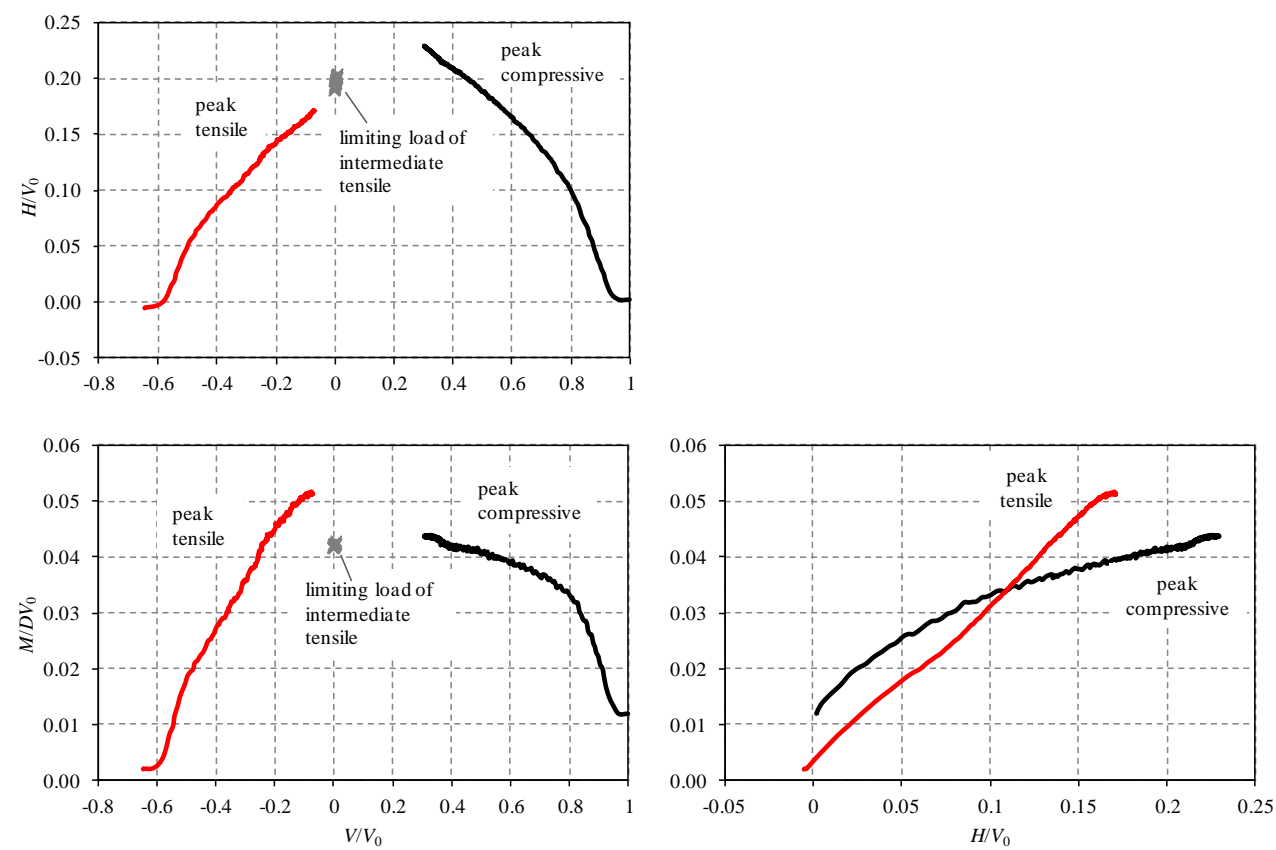
2 The following equation provides a reasonable and practical fit to the experimental data:

3

$4 f=\left(\frac{H}{h_{0} V_{0}}\right)^{2}+\left(\frac{M / D}{m_{o} V_{0}}\right)^{2}-\frac{2 e H M / D}{h_{0} m_{0} V_{0}^{2}}-\left(\frac{4}{(1+\chi)^{2}}\right)^{2}\left(\frac{V}{V_{0}}+\chi\right)^{2}\left(1-\frac{V}{V_{0}}\right)^{2}=0$

5 where $h_{0}$ and $m_{0}$ define the peak ratios of $H / V_{0}$ and $M / D V_{0}$ in the $V H(M=0)$ and $V M(H=0)$

6 planes, $e$ defines the eccentricity of the cross-section in the $H M$ plane and $\chi$ is the tensile capacity ratio $V_{\mathrm{T}} / V_{0}$.

9 For the convenience of optimisation, a generalised non-vertical force is defined as:

$Q=\sqrt{\left(\frac{H}{h_{0}}\right)^{2}+\left(\frac{M / D}{m_{o}}\right)^{2}-\frac{2 e H M / D}{h_{0} m_{0}}}$

11 allowing the yield surface to be simplified to:

$f=\left(\frac{Q}{V_{0}}\right)^{2}-\left(\frac{4}{(1+\chi)^{2}}\right)^{2}\left(\frac{V}{V_{0}}+\chi\right)^{2}\left(1-\frac{V}{V_{0}}\right)^{2}=0$

14 By using Eq. 8, the load path of a swipe test in the VHM space is simplified to a path in the $V Q$ plane. Least squares regression analysis was performed for each complete set of compressive swipe tests at different depths. As the pure vertical tests indicate a tensile capacity ratio of 0.6 , and indeed the best-fit $\chi$ values found by optimisation are around 0.6 (Zhang et al. 2013), the $\chi$ value is held at 0.6 for simplicity. Table 3 collates the optimised parameters for the three embedment depths and Figure 11 compares all the 22 swipe tests against Eq. 9 in the $V Q$ plane (note only the limiting loads are shown for the four intermediate tensile swipe tests). It is illustrated that all the compressive swipes bond closely around the fitted surface. 
1 Although the tensile swipes are presented in Figure 11, they were not included in the fitting

13 To further illustrate the fit, the load paths of swipe tests performed from peak compressive 14 process. Nonetheless, tests PTS1 and PTS2 with $u / D \theta \geq 0$ compare closely to the surface determined by the compressive swipes. However, tests PTS3 and PTS4 with $u / D \theta<0$ locate inside the yield surface. Similar observations can be made for the swipes performed from intermediate tensile load (i.e. tests ITS1 and ITS3 with $u / D \theta \geq 0$ reach limiting loads that are consistent with the fitted surface, but, tests ITS 2 and ITS 4 with $u / D \theta<0$ fall inside of the surface). No conclusive explanation for this can be offered at this stage.

Table 3. Summary of best-fit parameters.

\begin{tabular}{ccccc}
\hline Parameters & $h_{0}$ & $m_{0}$ & $e$ & \\
\hline $0.7 D$ & 0.182 & 0.089 & 0.380 & \\
$1.0 D$ & 0.198 & 0.092 & 0.244 & 0.6 \\
$1.45 D$ & 0.242 & 0.094 & 0.150 & \\
\hline
\end{tabular}

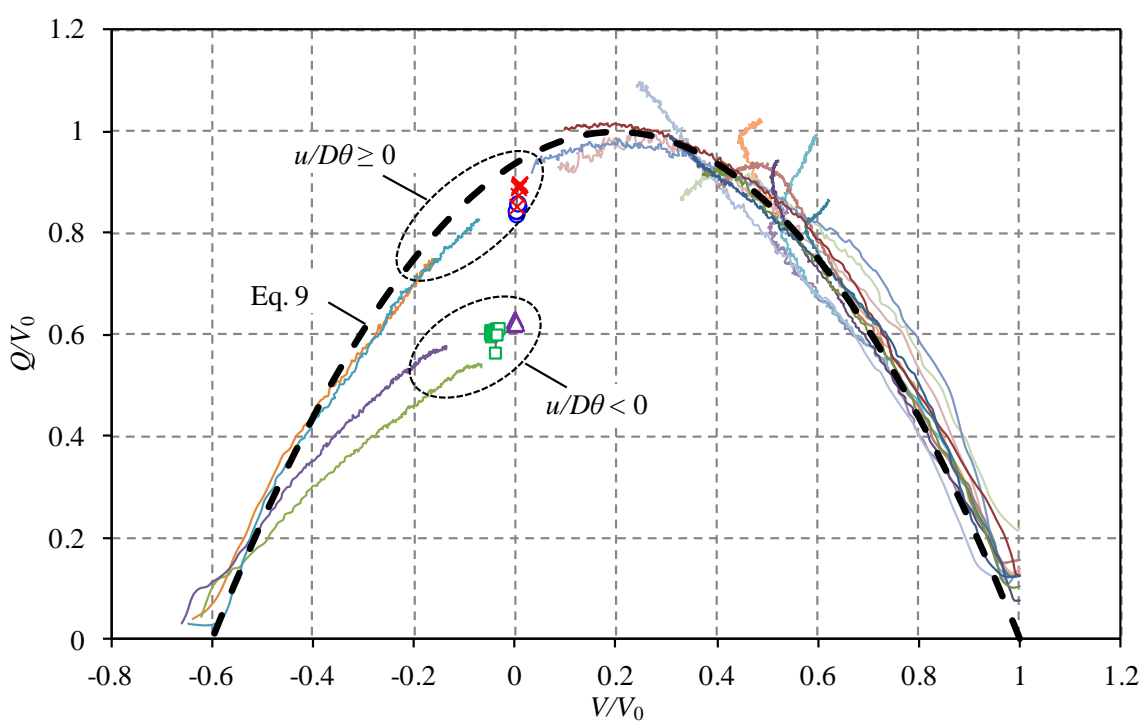

Figure 11. Swipe tests against the fitted surface in the $V Q$ plane and peak tensile vertical loads at $1.45 D$ are projected onto the $H M$ plane in Figure $12 \mathrm{a}$ and 
1 Figure $12 \mathrm{~b}$ respectively. Data points at discrete vertical load levels $\left(V / V_{0}=0.8,0.7,0.6,0.5\right.$

2 swipes. and 0.4$)$ for the compressive swipes and $\left(V / V_{0}=-0.5,-0.4,-0.3\right.$ and -0.2$)$ for the tensile swipes are compared with corresponding cross-sections of the fitted yield surface. As a load combination $(V, H, M)$ has the same effect as $(V,-H,-M)$ on the footing, the experimental data is also plotted in the diagonally opposite quadrant. The fitted surface describes the compressive swipes very well. The yield surface also compares closely to the data of the tensile swipes in the $(+H,+M)$ and $(-H,-M)$ quadrants. However, it is un-conservative compared to the data in the $(-H, M)$ and $(H,-M)$ quadrants. A better fit to the tensile swipes is possible by performing a separate regression analysis on those test data, but will require a different set of yield surface parameters. In practical situations, the moment on the foundation is often caused by the environmental load $(H)$ acted at an elevated height. Therefore, $H$ and $M$ are normally of the same sign, i.e. locate in the $(+H,+M)$ and $(-H,-M)$ quadrants. For simplicity, the yield surface adopts the best fit parameters evaluated from the compressive

$$
\text { pes. }
$$

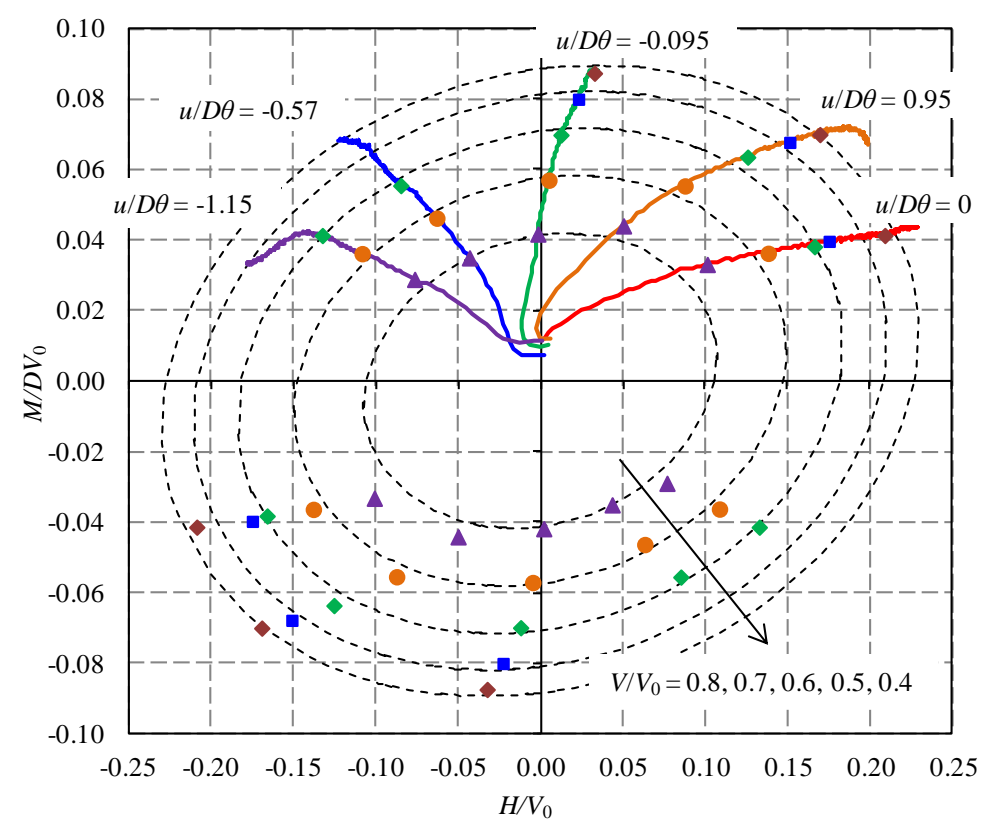


(a) Swipes from peak compressive vertical load testing peaks at an intermediate vertical load level $\left(V / V_{0} \approx 0.46\right)$ and the capacity diminishes

\section{Discussion on the yield surface}

Figure 13 compares the cross-sections of the yield surface in the normalised $V H(M=0)$ and $V M(H=0)$ planes derived from (i) the current centrifuge tests, (ii) the $1 \mathrm{~g}$ experiments of Martin and Houlsby (2000), and (iii) the finite element analyses of Zhang et al. (2011) of a wished in place spudcan with complete backflow. On these two planes, Eq. 7 indicates a parabolic interaction envelope, similar to the $1 \mathrm{~g}$ surface. However, the location of the peak differs. The envelope based on the centrifuge results peaks at $V / V_{0}=0.2$, implying significant combined bearing capacity even under tensile vertical load. The envelope developed from $1 \mathrm{~g}$ to zero when the vertical load approaches zero. This is related to the different backflow and levels of suction between the centrifuge and $1 \mathrm{~g}$ tests, as also discussed in Vlahos et al.

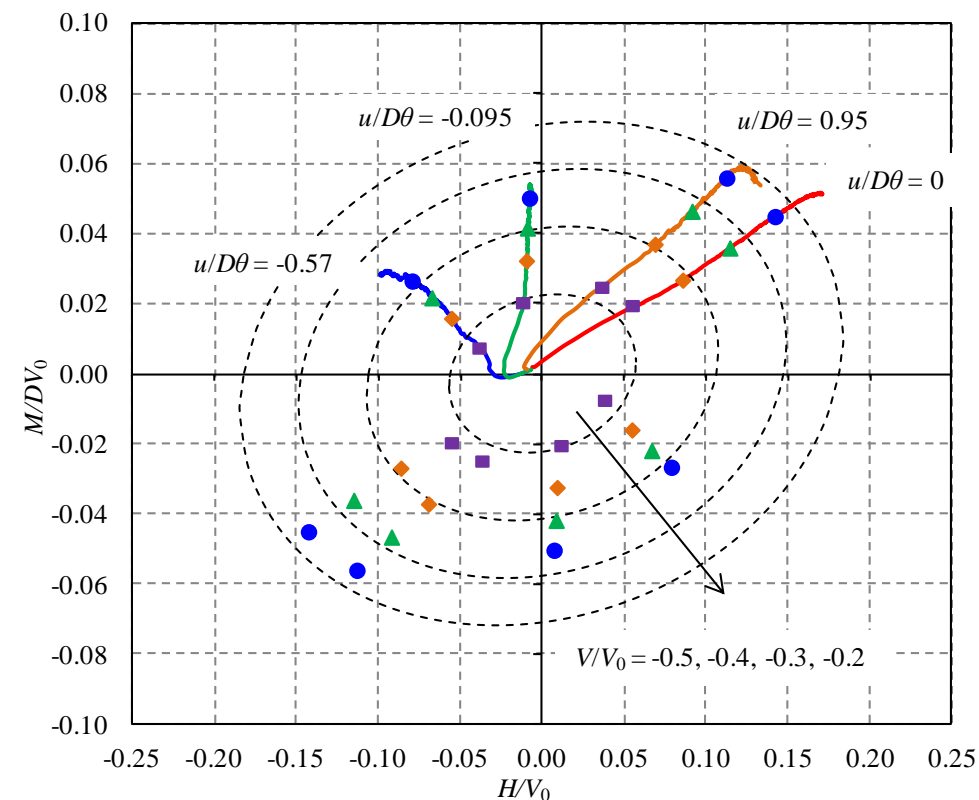

(b) Swipes from peak tensile vertical load Figure 12. Experimental data against the fitted yield surface in the normalised $H M$ plane 
1 (2008). The numerical analyses suggest elliptical interaction envelopes in these two planes

2 (that differ in shape between the $V H(M=0)$ and the $V M(H=0)$ planes, and both are larger

3 than the envelope evaluated from the centrifuge results). The numerically derived envelopes

4 peak at zero vertical load due to the assumption of the bonded footing-soil interface and the

5 Tresca yield criterion for the soil (thus the same tensile capacity as the compressive capacity 6 would be calculated).

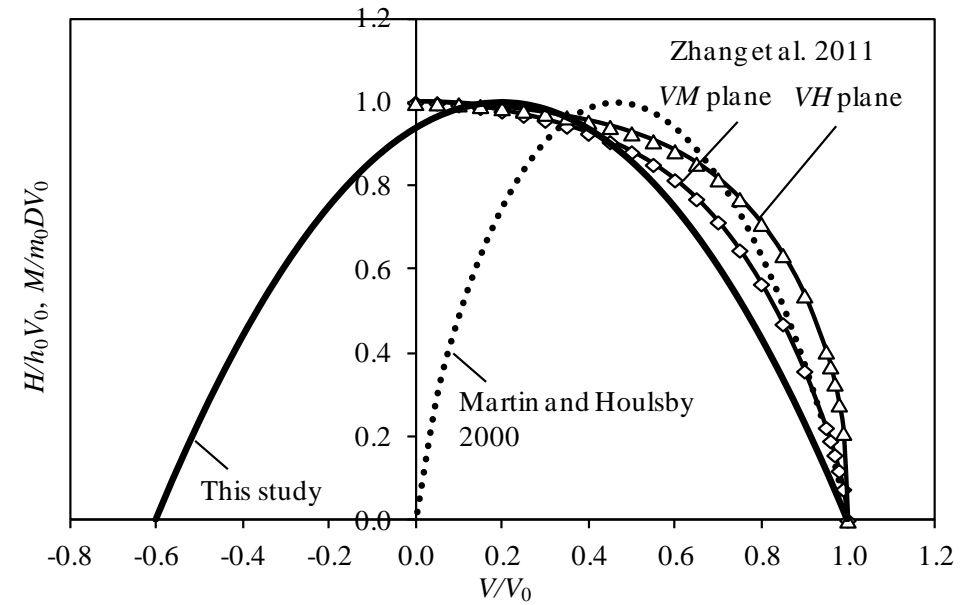

Figure 13. Comparison of yield surface shape in the normalised $V H(M=0)$ and $V M(H=0)$ planes

On the $V H$ and $V M$ planes, the current ISO guidelines recommend that the interaction envelope evolutes progressively from a parabola similar to Martin and Houlsby's envelope (except that it peaks at $V / V_{0}=0.5$ ) for a surface spudcan to an ellipse for a spudcan with embedment ratio $(w / D)$ equal to or greater than 2.5. However, the current centrifuge results seem not to support this evolution.

While the shape of yield surface is determined by the equation form (e.g. parabolic vs elliptical), the size of surface in the normalised load space is determined by the parameters $h_{0}$ and $m_{0}$. In Figure 14, the centrifuge results show that the values of $h_{0}$ and $m_{0}$ increase with embedment, especially $h_{0}$. This is in contrast to the $1 \mathrm{~g}$ test results, where $h_{0}$ and $m_{0}$ were 


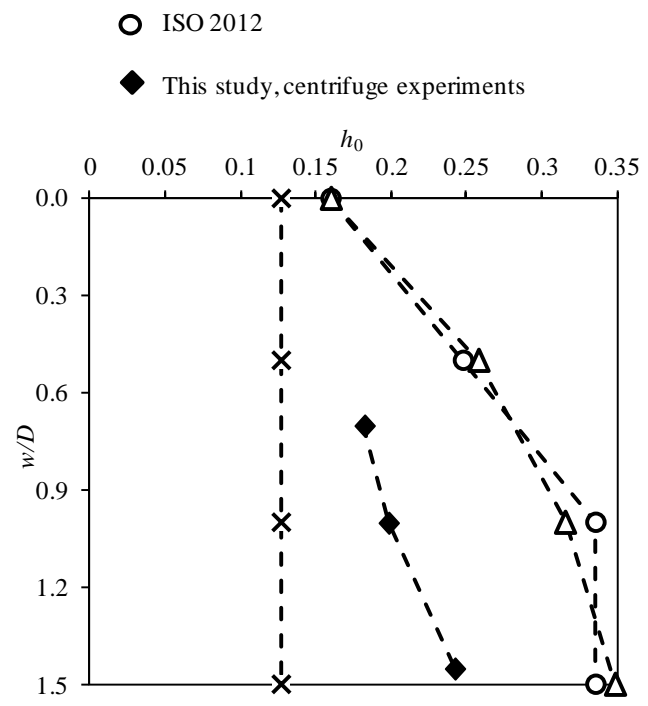

12

13

14

15

constant with depth. The centrifuge $h_{0}$ and $m_{0}$ values are also considerably higher, indicating increased bearing capacity due to backflow. Although the wished in place numerical analyses successfully capture this trend, the magnitude is overestimated as the remoulding and soil displacement during the installation process are not accounted for. The ISO guidelines recommend $h_{0}$ and $m_{0}$ values increase with embedment depth for spudcan in soft clay site based primarily on limited wished in place numerical analyses (of Templeton et al. 2005; Templeton 2009). Although a method is provided to correct for soil remoulding, the resulting $h_{0}$ and $m_{0}$ values according to ISO are still overly optimistic when compared to these experimentally measured values. This is shown in Figure 14, noting that the ISO data points are based on $S_{\mathrm{t}}=2.2$ with assumption of fully remoulded backflow and a projected horizontal area to vertical area ratio of 0.31 , relevant to the centrifuge experimental conditions.

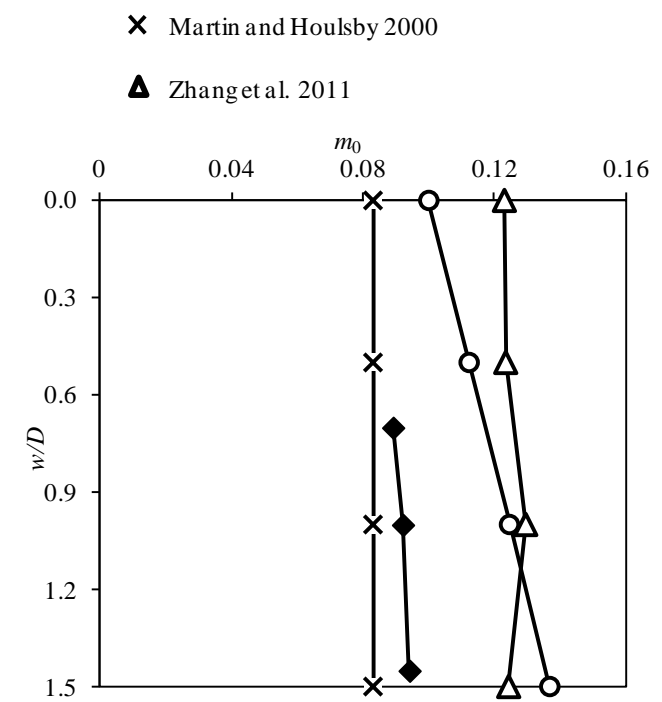

X Martin and Houlsby 2000

A Zhangetal. 201

Figure 14. Variation of $h_{0}$ and $m_{0}$ with embedment depth

Figure 15 compares the eccentricity of the $H M$ cross-sections of the yield surfaces derived from the centrifuge tests, the $1 \mathrm{~g}$ experiments and the finite element analyses. The centrifuge 
results show that eccentricity reduces with embedment, consistent with the findings from

2 finite element analyses. Contrary to this, the eccentricity of the surface derived from the $1 \mathrm{~g}$

3 experimental does not change with depth. The footing essentially behaves like a surface

4 foundation since no significant backflow was present in the tests.

8 Elasticity

9 Linear elastic response is assumed for load combinations inside the yield surface. The

$\left\{\begin{array}{l}\delta V \\ \delta H \\ \delta M\end{array}\right\}=\frac{G D}{8}\left[\begin{array}{ccc}4 K_{\mathrm{v}} & 0 & 0 \\ 0 & 4 K_{\mathrm{H}} & 2 K_{\mathrm{C}} D \\ 0 & 2 K_{\mathrm{C}} D & K_{\mathrm{M}} D^{2}\end{array}\right]\left\{\begin{array}{c}\delta w_{\mathrm{e}} \\ \delta u_{\mathrm{e}} \\ \delta \theta_{\mathrm{e}}\end{array}\right\}$

where $G$ is the shear modulus of the soil at current plastic embedment $\left(w_{\mathrm{p}}\right)$ and $K_{\mathrm{V}}, K_{\mathrm{H}}, K_{\mathrm{M}}$

14 and $K_{\mathrm{C}}$ are dimensionless stiffness coefficients that have been already defined by the finite

relationship between the increments of load $(\delta V, \delta H, \delta M)$ and the corresponding elastic displacements $\left(\delta w_{\mathrm{e}}, \delta u_{\mathrm{e}}, \delta \theta_{\mathrm{e}}\right)$ is:

element analyses of Zhang et al. (2012b). The coefficients reported in Zhang et al. (2012b)

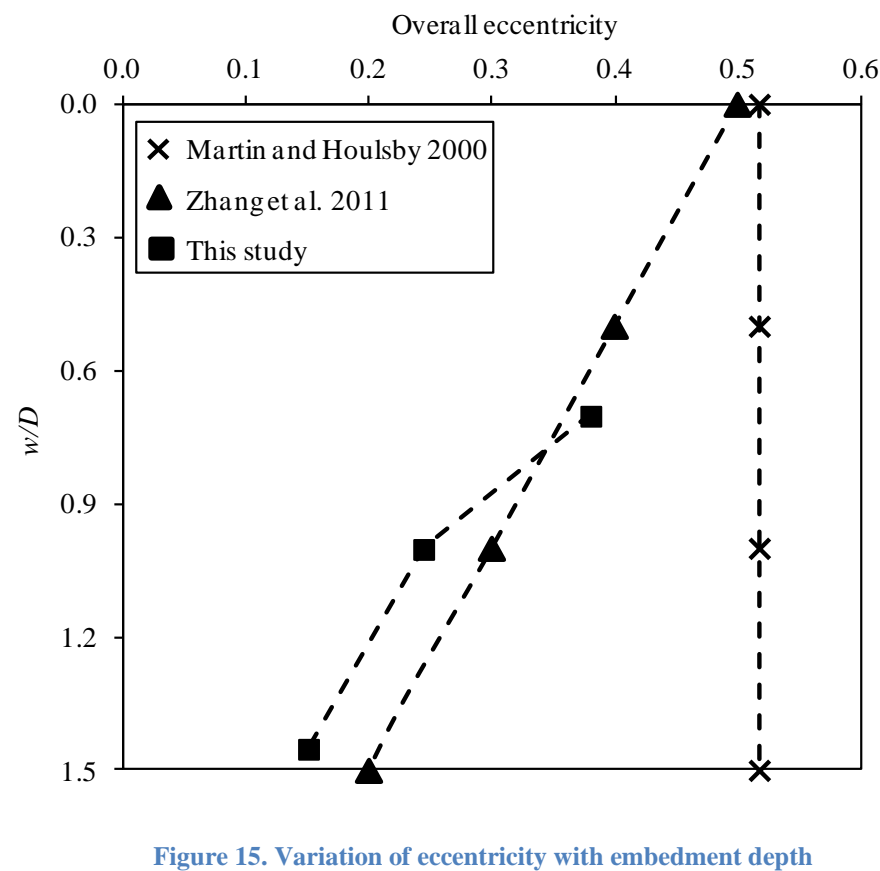


are representative of a spudcan shaped footing buried in backflow soil and provide for a

\begin{tabular}{ccccc}
\multicolumn{6}{c}{ Table 4. Representative elastic stiffness coefficients (after Zhang et al. 2012b). } \\
\hline$w / D$ & $K_{\mathrm{V}}$ & $K_{\mathrm{H}}$ & $K_{\mathrm{M}}$ & $K_{\mathrm{C}}$ \\
\hline 0.7 & 21.04 & 12.99 & 11.60 & 1.24 \\
1.0 & 18.63 & 12.66 & 11.51 & 1.27 \\
1.45 & 17.63 & 12.61 & 11.56 & 1.23 \\
\hline
\end{tabular}

8 For interpretation of the radial tests results and in the retrospective simulations reported in 9 this paper, the rigidity index $I_{\mathrm{r}}=G / s_{\mathrm{u} 0}$ was evaluated based on the unload-reload stiffness observed in the vertical tests (and by using the dimensionless elastic stiffness coefficient reported in Zhang et al. (2012b) according to Eq. 10). An average value of $I_{\mathrm{r}}=50$ was found to fit the experimental data well.

14 Flow rule

The flow rule dictates the direction of plastic flow during an elasto-plastic increment. In this model, a plastic potential surface with a similar form to the yield surface is proposed:

$g=\left(\frac{H}{\alpha_{\mathrm{h}} h_{0} V_{0}^{\prime}}\right)^{2}+\left(\frac{M / D}{\alpha_{\mathrm{m}} m_{0} V_{0}^{\prime}}\right)^{2}-\frac{2 e H M / D}{\alpha_{\mathrm{h}} \alpha_{\mathrm{m}} h_{0} m_{0} V_{0}^{\prime 2}}-\alpha_{\mathrm{v}}{ }^{2} \beta_{12}{ }^{2}\left(\frac{V}{V_{0}^{\prime}}+\chi\right)^{2 \beta_{1}}\left(1-\frac{V}{V_{0}^{\prime}}\right)^{2 \beta_{2}}=0$

where

19

$$
\beta_{12}=\frac{\left(\beta_{1}+\beta_{2}\right)^{\left(\beta_{1}+\beta_{2}\right)}}{\beta_{1}^{\beta_{1}} \beta_{2}^{\beta_{2}}(1+\chi)^{\left(\beta_{1}+\beta_{2}\right)}}
$$

$V_{0}^{\prime}$ is the dummy $V_{0}$ value of the plastic potential surface that intersects the yield surface at

21 the current load point $(V, H, M)$. The non-association parameters $a_{\mathrm{v}}, a_{\mathrm{h}}, a_{\mathrm{m}}, \beta_{1}$ and $\beta_{2}$ are used 
1 to adjust the shape of the surface. For $a_{\mathrm{v}}=a_{\mathrm{h}}=a_{\mathrm{m}}=\beta_{1}=\beta_{2}=1$, Eq. 12 is equivalent to Eq. 7,

simulating associated flow.

In the following sub-sections, the development of the proposed plastic potential surface is explained. .

\section{Plastic flow in the HM plane}

According to plasticity theory the ratio of plastic horizontal displacement to rotation can be evaluated as

$\frac{\delta u_{\mathrm{p}}}{D \delta \theta_{\mathrm{p}}}=\frac{\partial g / \partial H}{\partial g / \partial(M / D)}=\frac{\left(\frac{\alpha_{\mathrm{m}}}{\alpha_{\mathrm{h}}}\right)\left(\frac{m_{0}}{h_{0}}\right)\left(\frac{H}{M / D}\right)-e}{\left(\frac{\alpha_{\mathrm{h}}}{\alpha_{\mathrm{m}}}\right)\left(\frac{h_{0}}{m_{0}}\right)-e\left(\frac{H}{M / D}\right)}$

where $\delta u_{\mathrm{p}}$ and $\delta \theta_{\mathrm{p}}$ are plastic horizontal and rotational displacement increments respectively.

(1)

When $a_{\mathrm{h}}=a_{\mathrm{m}}=1$, Eq. 13 represents associated flow in the $H M$ plane. In Figure 16, the measured plastic displacement ratios $\delta u_{\mathrm{p}} / D \delta \theta_{\mathrm{p}}$ in the swipe tests are compared with the prediction of associated flow (for clarity this is only shown for depth of $0.7 D$; however, the results are similar for other depths). The experimental plastic displacements were obtained by subtracting the calculated elastic components from the prescribed total displacements. With the test data falling on both sides of the associated prediction, an associated flow appears a good first estimation, though the associated assumption consistently under-estimates the absolute plastic displacement ratio $\left(\left|\delta u_{\mathrm{p}} / D \delta \theta_{\mathrm{p}}\right|\right)$ at a given $D H / M$ ratio. However, when $a_{\mathrm{h}}=$ $1.0, a_{\mathrm{m}}=1.35$, the predicted plastic displacement ratios match the measured data very well for all depths, as illustrated by the example shown in Figure 16 for $0.7 D$. 


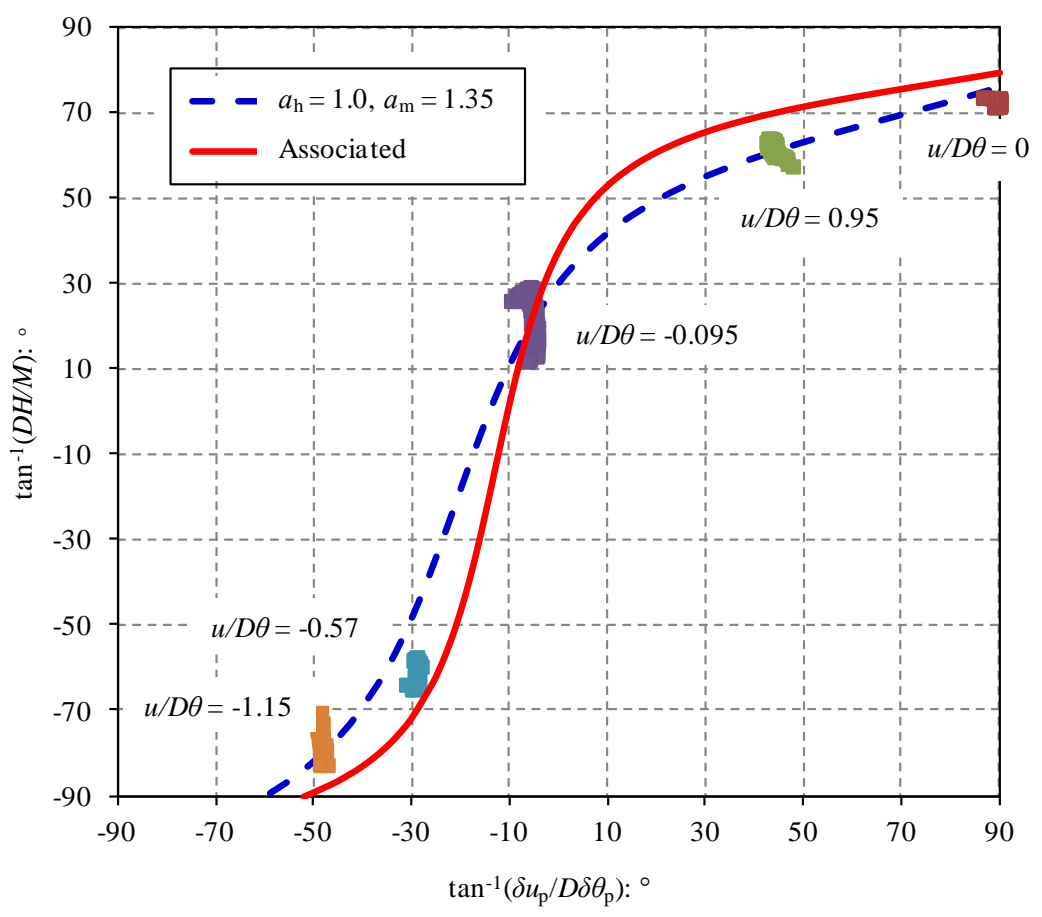

\section{$4 \quad$ Plastic flow in the VH and VM planes}

5

6 In the $V H$ and $V M$ planes, radial displacement tests were performed to evaluate the flow rule.

7 Figure 17 presents the load paths of four radial tests (R8, R9, R12 and R13 in Table 2) at

$81.45 D$, which were performed from a net vertical force of around zero (achieved through 0.8

$9 \mathrm{~mm}$ of upwards movement following initial penetration). The horizontal and moment loads

10 on the spudcan are expressed as the generalised non-vertical force $Q$ according to Eq. 8 .

11 Yield surfaces with different $V_{0}$ values are shown against the load paths, illustrating their expansion during the radial displacement tests. 


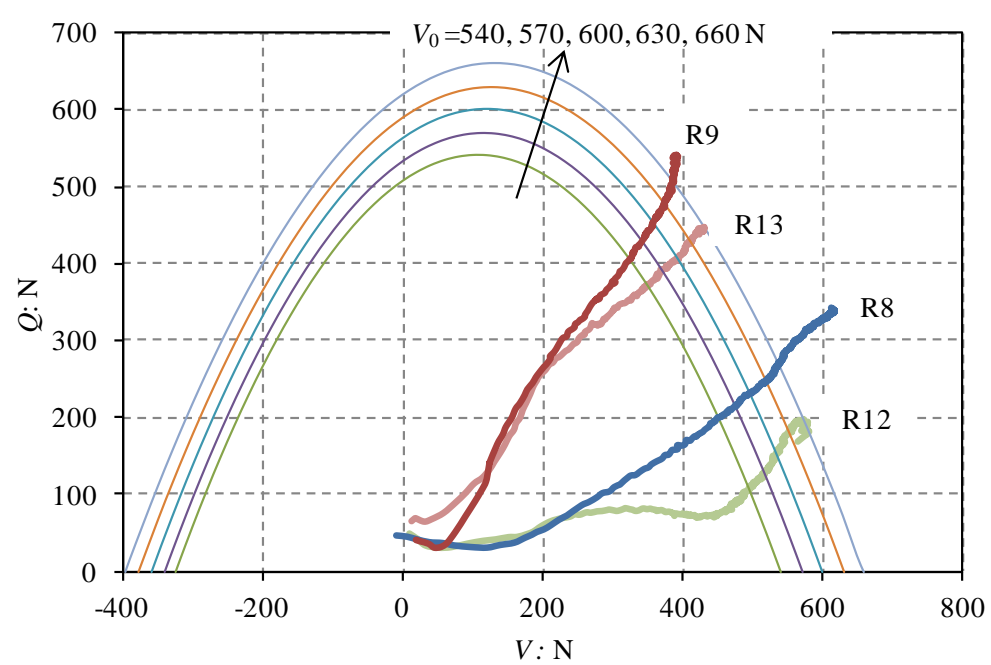

4 If associated flow is assumed,

$5 \quad \frac{\delta q_{\mathrm{p}}}{\delta w_{\mathrm{p}}}=\frac{\partial f / \partial Q}{\partial f / \partial V}$

6 where $\delta q_{\mathrm{p}}$ is the generalised plastic displacement conjugate to $Q$, which can be expressed as:

$7 \quad \delta q_{\mathrm{p}}=\sqrt{\frac{1}{1-e^{2}}\left[\left(h_{0} \delta u_{\mathrm{p}}\right)^{2}+\left(m_{0} D \delta \theta_{\mathrm{p}}\right)^{2}+2 e\left(h_{0} \delta u_{\mathrm{p}}\right)\left(m_{0} D \delta \theta_{\mathrm{p}}\right)\right]}$

8 as demonstrated in Cassidy et al. (2002a).

10 In Figure 18, the plastic displacements of the radial displacement tests performed at both 11 depths of $0.7 D$ and $1.45 D$ are compared with prediction of Eq. 14, which clearly shows that 12 the associated flow does not describe the experimental data satisfactorily (Note R5, R6, R7,

$13 \mathrm{R} 10$ and R11 are not shown for $1.45 \mathrm{D}$ for clarity, though the comparison is similar).

15 Based on the plastic potential surface of Eq. 13, least squares regression was performed to find the optimal set of parameters to describe the radial displacement test data. For 
consistency with the $H M$ plane, $a_{\mathrm{h}}$ and $a_{\mathrm{m}}$ are constrained to be 1.0 and 1.35 respectively.

Further, $\beta_{1}$ and $\beta_{2}$ were constrained to be equal to ensure that the peak of the plastic potential occurred at $V / V_{0}^{\prime}=0.2$. Values of $a_{\mathrm{v}}=1.1, \beta_{1}=\beta_{2}=0.45$ were found to predict the experimental data well, as illustrated in Figure 18.
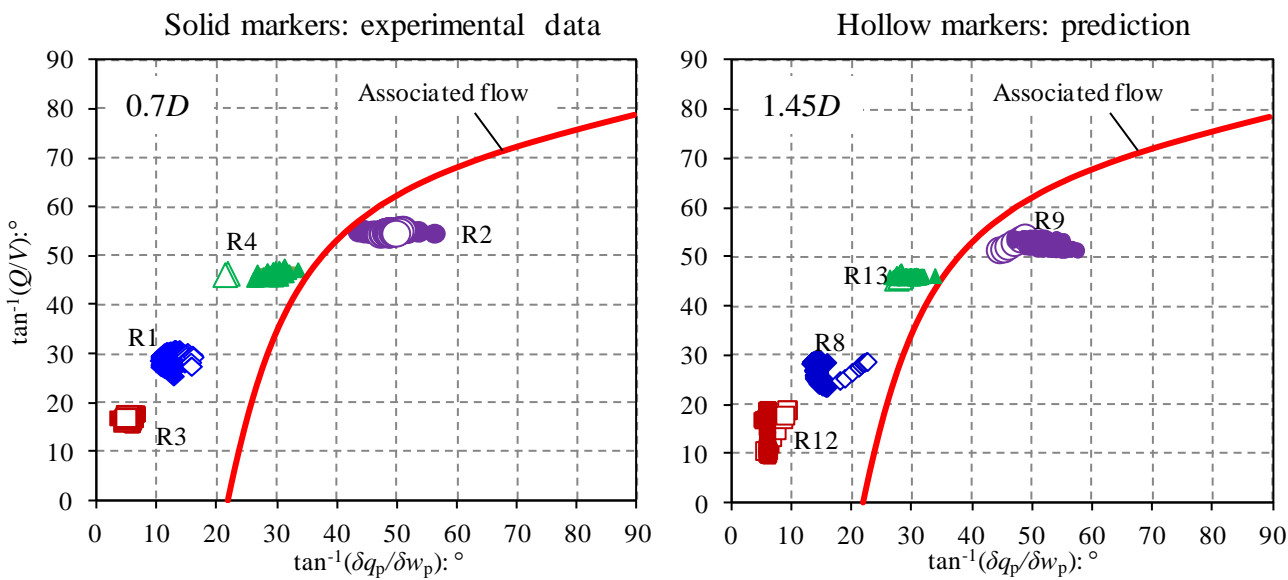

Figure 18. Plastic flow indicated by radial displacement tests

\section{RETROSPECTIVE ANALYSES}

The force resultant model has been implemented into a FORTRAN program and retrospective simulations of selected centrifuge tests have been performed to demonstrate the capabilities of the model. As the entire centrifuge program was displacement controlled, the input to the numerical analysis consisted of displacements identical to those imposed in the experiments, with the FORTRAN program calculating the spudcan reactions according to the model.

\section{Retrospective simulation of a pure vertical test}

Figure 19 compares the numerical simulation of a vertical test with the centrifuge experiment. A reasonably good match is demonstrated. The assumption of purely elastic behaviour within the yield surface can be observed to be slightly simplistic during the start of the extraction 
1 phase. A close simulation until $V=0$ can be observed (as expected as the shear modulus $G$ 2 was fit from the experiments) but after that the experiments see a more non-linear reduction 3 of stiffness than the model predicts.

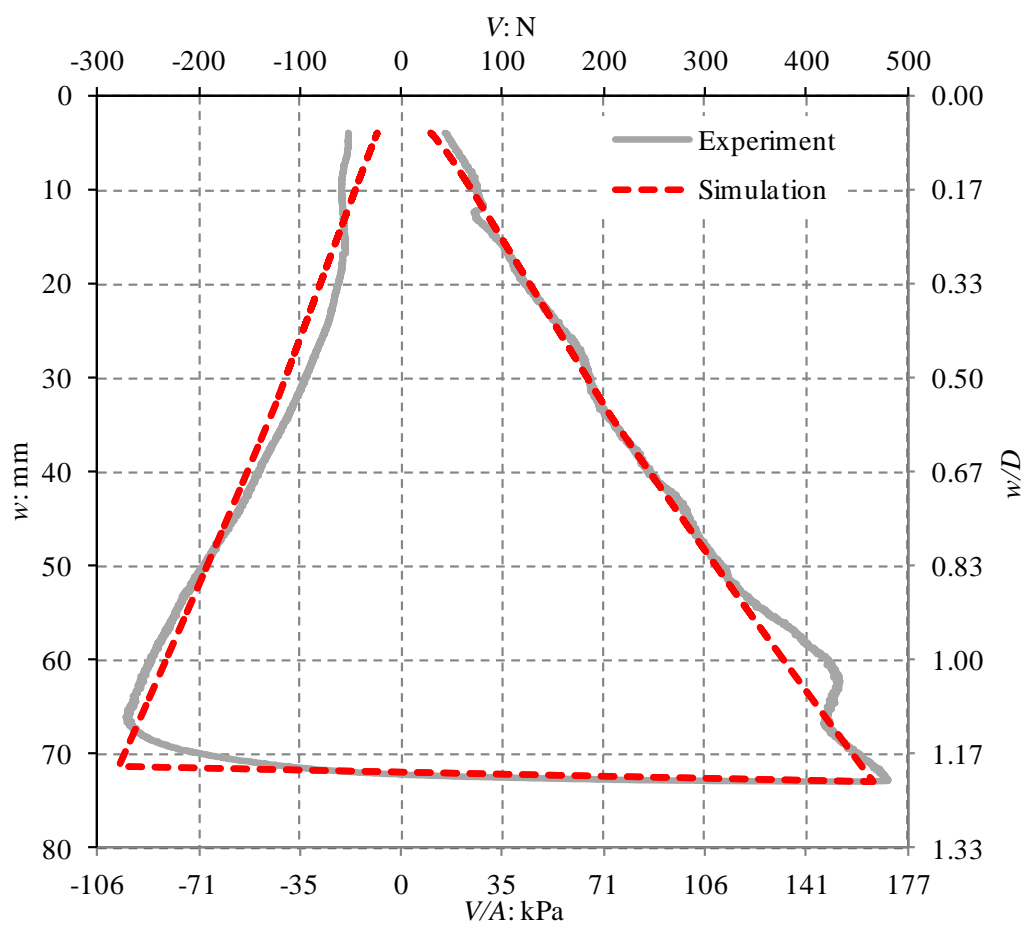

\section{$7 \quad$ Simulation of swipe tests}

8 Due to space limitations only two swipe tests are shown. Figure 20 shows the simulation of

9 swipe test PCS2 $(u / D \theta=0.95, w / D=0.7)$ against the experimental results. Both the load paths and load-displacement response are predicted well by the numerical simulation. 

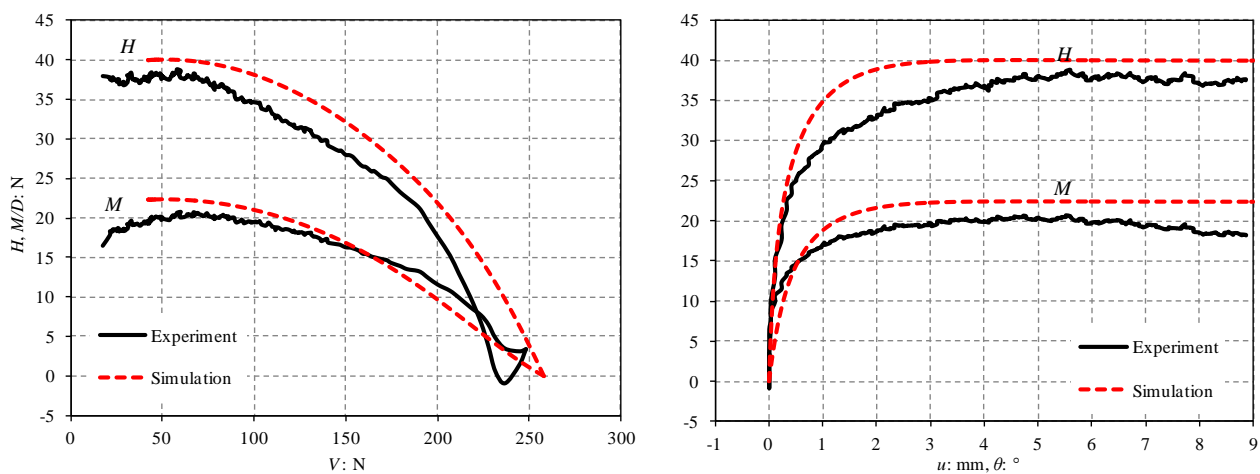

Figure 20. Simulation of swipe test PCS2

3 Figure 21 shows the simulation of the swipe test PTS2 $(u / D \theta=0.95, w / D=1.45)$, which was performed from peak tensile vertical load. It is demonstrated that the load path predicted by

5 the numerical simulation matches the experimental response well. However, the numerical

6 simulation terminates at a higher vertical load level, which is determined by the peak of the

7 plastic potential or the 'parallel point' (Tan 1990; Cassidy et al. 2002a) where the load state

8 does not change despite continuing deviatoric movements. According to the flow rule

9 adopted in this model, the parallel point occurs at $V / V_{0}{ }^{\prime}=0.2$ (the $V / V_{0}$ ratio at the termination point is also close to 0.2 , with its exact value dependent on the load path).
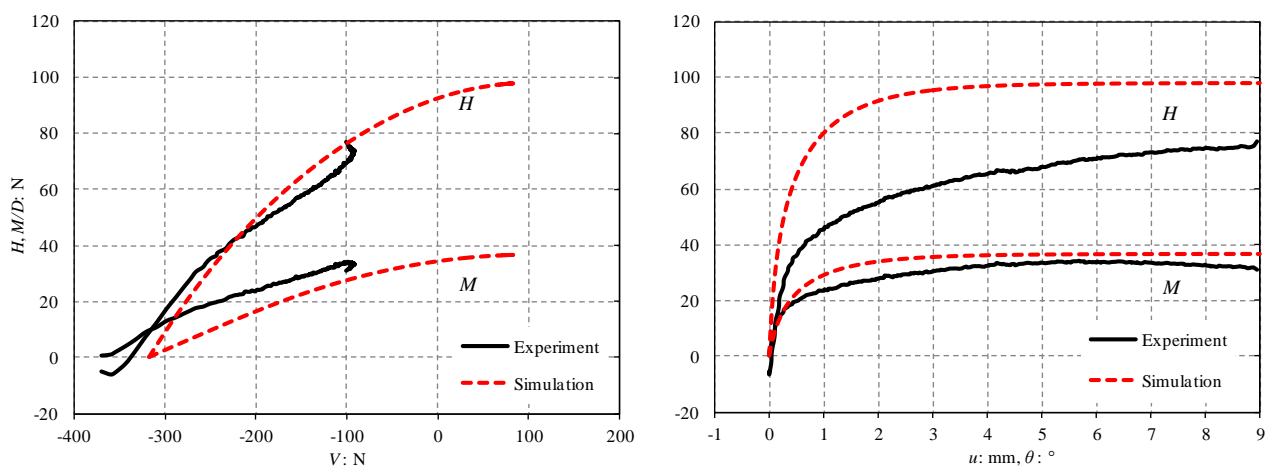
2 Figure 22 shows the simulation of radial test R6, in which the spudcan was displaced at a

3 fixed ratio of $u / w=1$ after the vertical load was unloaded elastically to approximately zero.

4 The model predicts that the loads on the spudcan will increase linearly (purely elastic 5 behaviour) until reaching the yield surface established during the initial vertical penetration.

6 The loads on the spudcan then move quickly along the expanding yield surface and finally "find" the location where the theoretical plastic displacement ratio matches the prescribed

8 (after the small fraction of elastic components is deducted). However, the experimental load 9 path does not have an obvious elastic-plastic transition point and this is a limitation in the single surface displacement hardening approach. A similar response is also reported for a

11 caisson foundation in clay (Cassidy et al. 2006). After reaching the yield surface, the simulation expands the yield surface at a similar location of the yield surface as the experiment results. This demonstrates that the plastic flow rule correctly predicts the displacements ratios. However, the magnitude of expansion predicted by the model is less than in the experiment. In other words, the yield surface of the foundation under the displacement path of the radial test is greater than the prediction by the vertical displacement hardening law. Such phenomenon has also been observed in similar tests on sand (Byrne and Houlsby 2001; Bienen et al. 2006) and improvements to the model framework were made by including the plastic horizontal and rotational displacements into the hardening law (radial hardening). This achieved better simulations of the experiments. However, this is not pursued

21 in the current model so as not to increase its complexity. It should be noted that the current model is conservative in terms of predicting the yield surface expansion by not incorporating 23 the radial hardening. 


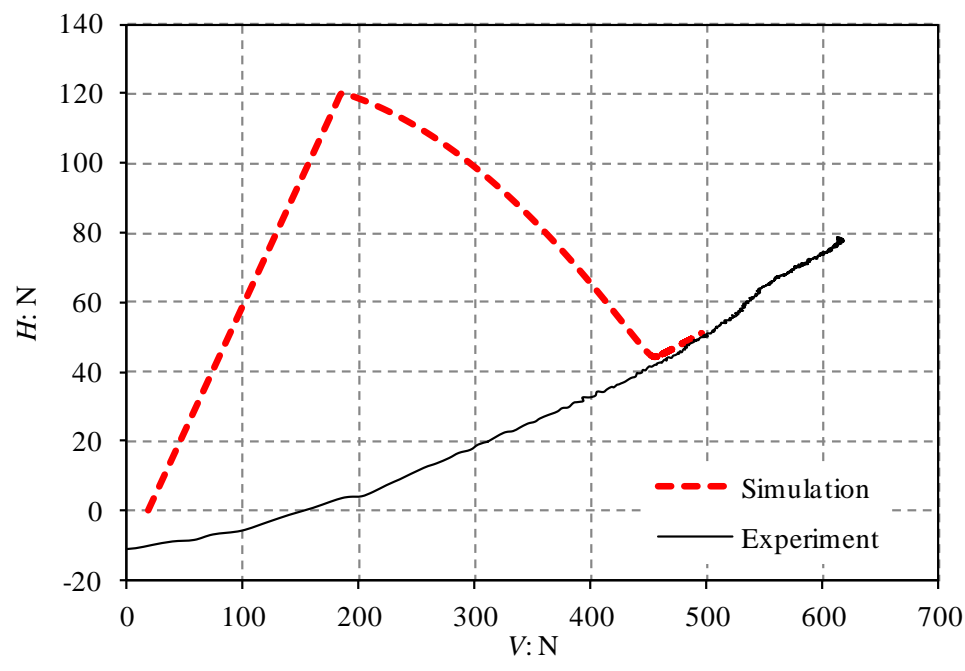

\section{CONCLUSIONS}

4 This paper presents a comprehensive set of centrifuge swipe tests that measured the combined bearing capacity of a typical spudcan foundation in soft clay at three different

6 embedment depths $(0.7 D, 1.0 D$ and $1.45 D)$ under compressive as well as tensile vertical load.

7 These tests confirmed that soil backflow (i) increases the size of the bearing capacity surface

8 and (ii) provides significant bearing capacity under tensile vertical load. The size of the

9 surface also increases with embedment depth. However, the magnitude of bearing capacity

10 enhancement due to the backflow is less than the recommendations by the current ISO

11 guidelines.

13 Although the ISO guidelines allow for advanced force resultant modelling in a jack-up 14 assessment, no guidance on how to achieve this is provided. Therefore, the test results 15 reported in this paper are used to develop a force resultant foundation model that describes 16 the load-displacement behaviour of the foundation under combined VHM loading. The model 17 uses existing elastic solutions based on finite element analyses and a hardening law derived 

from combined experimental and numerical investigations. The bearing capacity surface

9 The model predicts the general foundation behaviour well and is appropriate for predicting

evaluated from the swipe tests forms the yield surface of the plasticity model. Those swipe tests also reveal slightly non-associated plastic flow in the $H M$ plane. Additional centrifuge radial displacement tests were performed to investigate the plastic flow rule in the $V H$ and $V M$ planes and demonstrated significant non-associated behaviour in those two planes. An appropriate flow rule that scales the shape of the yield surface has been proposed for the model.

the pushover capacity of a mobile jack-up during a site-specific assessment analysis. Options

for model improvement have been highlighted, though these will increase model complexity.

The model has been developed from monotonic loading experiments and further developments are required for the model to capture the response to cyclic loading.

\section{ACKNOWLEDGEMENTS}

The first author is the recipient of a University of Western Australia SIRF scholarship and an Australia-China Natural Gas Technology Partnership Fund PhD top-up scholarship. The second author is the recipient of an ARC Future Fellowship (FT0990301) and holds the Chair of Offshore Foundations from the Lloyd's Register Foundation. He gratefully acknowledges this support. The third author acknowledges the funding support from an Australian Research Council (ARC) Postdoctoral Fellowship (DP11010163). 


\section{REFERENCES}

Bell, R. W. (1991). "The analysis of offshore foundations subjected to combined loading," MSc thesis, University of Oxford, UK.

Bienen, B., Byrne, B. W., Houlsby, G. T., and Cassidy, M. J. (2006). "Investigating sixdegree-of-freedom loading of shallow foundations on sand." Géotechnique, 56(6), $367-379$.

Bienen, B., and Cassidy, M. J. (2006). "Advances in the three-dimensional fluid-structuresoil interaction analysis of offshore jack-up structures." Marine Structures, 19(2-3), $110-140$

Bienen, B., and Cassidy, M. J. (2009). "Three-dimensional numerical analysis of centrifuge experiments on a model jack-up drilling rig on sand." Canadian Geotechnical Journal, 46(2), 208-224.

Byrne, B. W., and Houlsby, G. T. (2001). "Observations of footing behaviour on loose carbonate sands." Géotechnique, 51(5), 463-466.

Cassidy, M. J. (2012). "Experimental observations of the penetration of spudcan footings in silt." Géotechnique, 62(8), 727-732.

Cassidy, M. J., Byrne, B. W., and Houlsby, G. T. (2002a). "Modelling the behaviour of circular footings under combined loading on loose carbonate sand." Géotechnique, $52(10), 705-712$

Cassidy, M. J., Byrne, B. W., and Randolph, M. F. (2004). "A comparison of the combined load behaviour of spudcan and caisson foundations on soft normally consolidated clay," Géotechnique, 54(2), 91-106.

Cassidy, M. J., Randolph, M. F., and Byrne, B. W. (2006). "A plasticity model describing caisson behaviour in clay." Applied Ocean Research, 28(5), 345-358.

Cassidy, MJ, Taylor, RE, and Houlsby, GT (2001). "Analysis of jack-up units using a constrained New Wave methodology," Applied Ocean Research, 23(2001), 221-234.

Cassidy, MJ, Taylor, PH, Taylor, RE, and Houlsby, GT (2002b). "Evaluation of long-term extreme response statistics of jack-up platforms," Ocean Engineering, 29(2002), 1603-1631.

Chung, S. F., Randolph, M. F., and Schneider, J. A. (2006). "Effect of penetration rate on penetrometer resistance in clay." Journal of Geotechnical and Geoenvironmental Engineering, 132(9), 1188-1196.

Dean, E. T. R., James, R. G., Schofield, A. N., and Tsukamoto, Y. (1997). "Theoretical modelling of spudcan behaviour under combined load." Soils and Foundations, 37(2), $1-15$.

Dejong, J. T., Yafrate, N. J., and Degroot, D. J. (2011). "Evaluation of undrained shear strength using full-flow penetrometers." Journal of Geotechnical and Geoenvironmental Engineering, 137(1), 14-26.

Einav, I., and Randolph, M. F. (2005). "Combined upper bound and strain path methods for evaluating the penetration process." International Journal for Numerical Methods in Engineering, 63(14), 1991-2016.

Finnie, I. M. S. (1993). "Performance of shallow foundations in calcareous soils," PhD thesis, University of Western Australia, Perth, Australia.

Gan, C.T., Leung, C.F., Cassidy, M.J., Gaudin, C., Chow, Y.K. (2012). Effect of time on spudcan-footprint interaction in clay. Géotechnique, Vol. 62, No. 5, pp. 401-413.

Gaudin, C., Bienen, B., and Cassidy, M. J. (2011). "Investigation of the potential of bottom water jetting to ease spudcan extraction in soft clay." Géotechnique, 61(12), 10431054.

Gottardi, G., Houlsby, G. T., and Butterfield, R. (1999). "Plastic response of circular footings on sand under general planar loading." Géotechnique, 49(4), 453-469.

Hodder, M. S., White, D., and Cassidy, M. J. (2010). "Analysis of soil strength degradation during episodes of cyclic loading, illustrated by the T-Bar penetration test." International Journal of Geomechanics, 10(3), 117-123.

Hossain, M. S., Hu, Y., Randolph, M. F., and White, D. J. (2005). "Limiting cavity depth for spudcan foundations penetrating clay." Géotechnique, 55(9), 679-690. 
Hossain, M. S., and Randolph, M. F. (2009a). "New mechanism-based design approach for spudcan foundations on single layer clay." Journal of Geotechnical and Geoenvironmental Engineering, 135(9), 1264-1274.

Hossain, M. S., and Randolph, M. F. (2009b). "Effect of strain rate and strain sofening on the penetration resistance of spudcan foundations on clay " International Journal of Geomechanics, 9(3), 122-132.

Houlsby, G. T., and Cassidy, M. J. (2002). "A plasticity model for the behaviour of footings on sand under combined loading." Géotechnique, 52(2), 117-129.

House, A. R., Oliveira, J. R. M. S., and Randolph, M. F. (2001). "Evaluating the coefficient of consolidation using penetration tests." International Journal of Physical Modelling in Geotechnics, 1(3), 17-25.

ISO. (2012). "Petroleum and natural gas industries - Site-specific assessment of mobile offshore units - Part 1: Jack-ups, 19905-1." International Organization for Standardization.

Mana, D. S. K., Randolph, M. F., Gourvenec, S., and Hossain, M. S. (2012). "Failure mechanisms of skirted foundations in uplift and compression." International Journal of Physical Modelling in Geotechnics, 12(2), 47-62.

Martin, C. M., and Houlsby, G. T. (1999). "Jackup unit on clay: structural analysis with realistic modelling of spudcan behaviour." Offshore Technology Conference, Houston, USA, OTC 10996.

Martin, C. M., and Houlsby, G. T. (2000). "Combined loading of spudcan foundations on clay: laboratory tests." Géotechnique, 50(4), 325-338.

Martin, C. M., and Houlsby, G. T. (2001). "Combined loading of spudcan foundations on clay: numerical modelling." Géotechnique, 51(8), 687-699.

Ngo-Tran, C. L. (1996). "The analysis of offshore foundations subjected to combined loading," DPhil thesis, University of Oxford, UK.

Nova, R., and Montrasio, L. (1991). "Settlement of shallow foundations on sand." Géotechnique, 41(2), 243-256.

Purwana, O. A., Leung, C. F., Chow, Y. K., and Foo, K. S. (2005). "Influence of base suction on extraction of jack-up spudcans." Géotechnique, 55(10), 741-753.

Randolph, M., Low, H. E., and Zhou, H. (2007). "In situ testing for design of pipeline and anchoring systems." 6th International Offshore Site Investigation and Geotechnics Conference: Confronting New Challenges and Sharing Knowledge, London.

Randolph, M. F. (2004). "Characterization of soft sediments for offshore applications." 2nd International Conference on Site Characterization, Millpress Science Publishers, Rotterdam, Porto, Portugal, 209-231.

Randolph, M. F., and Hope, S. (2004). "Effect of cone velocity on cone resistance and excess pore pressure." International Symposium on Engineering Practice and Performance of Soft Deposites, Osaka, Japan, 147-152.

Schotman, G. J. M. (1989). "The effects of displacements on the stability of jackup spud-can foundations." 21st Offshore Technology Conference, Houston, Texas, U.S.A, OTC 6026.

SNAME. (2008). "Recommended practice for site specific assessment of mobile jack-up units." T\&R Bulletin 5-5A, 1st Ed., 3rd Rev., Society of Naval Architects and Marine Engineers, N.J.

Stewart, D. P. (1992). "Lateral loading of piled bridge abutments due to embankment construction," PhD thesis, University of Western Autralia, Perth, Australia.

Stewart, D. P., and Randolph, M. F. (1994). "T-bar penetration testing in soft clay." Journal of Geotechnical Engineering Division, 120(12), 2230-2235.

Tan, F. S. C. (1990). "Centrifuge and theoretical modelling of conical footings on sand," D.Phil thesis, Cambridge University, UK.

Taylor, R. N. (1995). "Geotechnical centrifuge technology". Blackie Academic \& Professional, Glasgow, UK

Templeton, J. S. (2009). "Spudcan fixity in clay, further results from a study for IADC." 12th Int. Conf. on The Jack-Up Platform Design, Construction \& Operation, London, UK. 
Templeton, J. S., Brekke, J. N., and Lewis, D. R. (2005). "Spud can fixity in clay, final findings of a study for IADC." 10th Int. Conf. on The Jack-Up Platform Design, Construction \& Operation, London, UK.

Thompson, R. (1996). "Developement of non-linear numerical models appropriate for the analysis of jack-up units," D.Phil. thesis, University of Oxford, UK.

Vlahos, G., Cassidy, M. J., and Martin, C. M. (2008). "Experimental investigation of the system behaviour of a model three-legged jack-up on clay." Applied Ocean Research, 30(4), 323-337.

Vlahos, G., Cassidy, M. J., and Martin, C. M. (2011). "Numerical simulation of pushover tests on a model jack-up platform on clay." Géotechnique, 61(11), 947-960.

Williams, M. S., Thompson, R. S. G., and Houlsby, G. T. (1998). "Non-linear dynamic analysis of offshore jack-up units." Computers and Structures, 69, 171-180.

Zhang, Y., Bienen, B., and Cassidy, M. J. (2013). "Development of a combined VHM loading apparatus for a geotechnical drum centrifuge." International Journal of Physical Modelling in Geotechnics, 13(1), 13-30.

Zhang, Y., Bienen, B., Cassidy, M. J., and Gourvenec, S. (2011). "The undrained bearing capacity of a spudcan foundation under combined loading in soft clay " Marine Structures, 24(4), 459-477.

Zhang, Y., Bienen, B., Cassidy, M. J., and Gourvenec, S. (2012a). "Undrained bearing capacity of deeply buried flat circular footings under general loading." Journal of Geotechnical and Geoenvironmental Engineering, 138(3), 385-397.

Zhang, Y., Cassidy, M. J., and Bienen, B. (2012b). "Elastic stiffness coefficients for an embedded spudcan in clay." Computers and Geotechnics 42(2012), 89-97. 
1 LIST OF NOTATIONS

$2 A$ vertical bearing area of the spudcan

$3 c_{\mathrm{v}} \quad$ coefficient of consolidation

$4 \quad D \quad$ diameter of the footing

$5 e$ eccentricity of the $H M$ cross-sections of the yield surface

$6 \quad F_{\mathrm{b}} \quad$ buoyancy force

$7 \quad G \quad$ soil shear modulus

$8 \quad H \quad$ horizontal load on the footing

$9 h_{0} \quad$ peak ratio of $H / V_{0}$ in the $V H(M=0)$ plane

$10 I_{\mathrm{r}} \quad$ rigidity index

$11 K_{\mathrm{V}}, K_{\mathrm{H}}, K_{\mathrm{M}}, K_{\mathrm{C}} \quad$ dimensionless elastic stiffness coefficients

$12 L R P$ load reference point of the footing

$13 M \quad$ moment load on the footing

$14 m_{0} \quad$ peak ratio of $M / D V_{0}$ in the $V M(H=0)$ plane

$15 N_{\mathrm{c}} \quad$ vertical bearing capacity factor

$16 N_{\mathrm{cd}}$ deep vertical bearing capacity factor

$17 N_{\text {cd_ideal }}$ deep vertical bearing capacity factor in an ideally non-strain softening soil

$18 N_{\mathrm{cs}} \quad$ shallow vertical bearing capacity factor

$19 N_{\text {c__ideal }}$ shallow vertical bearing capacity factor in an ideally non-strain softening soil

$20 N_{\text {T-bar }}$ bearing capacity factor for the miniature T-bar penetrometer

$21 \quad Q \quad$ generalised non-vertical force

$22 q_{\mathrm{p}} \quad$ plastic non-vertical displacement conjugate to $Q$

$23 \quad S_{\mathrm{t}} \quad$ sensitivity of the soil

$24 s_{\mathrm{u}} \quad$ undrained shear strength of the soil

$25 s_{\text {uо }} \quad$ undrained shear strength at the current plastic embedment depth of the footing

$26 u$ horizontal footing displacement

$27 u_{\mathrm{e}} \quad$ elastic horizontal footing displacement

$28 u_{\mathrm{p}} \quad$ plastic horizontal footing displacement

$29 \dot{u} \quad$ horizontal displacement velocity

$30 \quad V \quad$ vertical load on the footing

31 Vol volume of soil displaced by the spudcan

$32 \quad V_{0} \quad$ peak vertical compressive capacity

$33 V_{0}^{\prime} \quad$ dummy peak vertical compressive capacity for the plastic potential surface

$34 \quad V_{\mathrm{T}} \quad$ peak vertical tensile capacity 
$1 V_{\text {total_C }}$ vertical capacity of the footing to resist compressive external load

$2 V_{\text {total_T }}$ vertical capacity of the footing to resist tensile external load

$3 w$ vertical footing displacement

$4 \quad w_{\mathrm{e}} \quad$ elastic vertical footing displacement

$5 \quad w_{\mathrm{p}} \quad$ plastic vertical footing displacement

$6 \dot{W} \quad$ vertical penetration velocity

$7 \theta \quad$ rotation of the footing

$8 \theta_{\mathrm{e}} \quad$ elastic rotation of the footing

$9 \theta_{\mathrm{p}} \quad$ plastic rotation of the footing

$10 \dot{\theta} \quad$ rotational velocity

$11 \chi \quad$ ratio of peak tensile capacity to peak compressive capacity

$12 \gamma^{\prime} \quad$ effective unit weight of the soil

$13 \sigma_{\mathrm{v} 0}{ }^{\prime}$ effective vertical consolidation pressure

$14 \delta_{\text {rem }}$ the inverse of soil sensitivity

$15 \xi_{95} \quad$ cumulative shear strain required for $95 \%$ remoulding

$16 \xi_{\mathrm{b}} \quad$ average cumulative shear strain experienced by the soil as it traverses the flow 17 mechanism around the spudcan

$18 a_{\mathrm{h}}, a_{\mathrm{m}}, a_{\mathrm{v}}, \beta_{1}, \beta_{2} \quad$ non-association parameters 
Table 1. Summary of the swipe testing programme followed

3 Table 2. Summary of the radial displacement testing programme followed

4 Table 3. Summary of best-fit parameters

Table 4. Representative elastic stiffness coefficients (after Zhang et al. 2012b)

\section{LIST OF FIGURE CAPTIONS}

Figure 1. A typical spudcan foundation under combined VHM loading and corresponding displacements

Figure 2. Assembly of the VHM load apparatus (after Zhang et al. 2013)

Figure3. Undrained shear strength profile determined from T-bar tests

Figure 4. Soil sensitivity determined from cyclic T-bar tests

Figure 5. Schematic illustration of swipe test load paths (modified after Gottardi et al. 1999)

Figure 6. Schematic illustration of radial displacement test load paths

Figure 7. Vertical load response during penetration and extraction

Figure 8. Vertical bearing capacity factor of the spudcan

Figure 9. Load paths of similar swipe tests (PCS2, PCS7 and PCS11) performed at different embedment depths

Figure 10. Load path of similar swipes (PCS10, ITS3 and PTS1) performed from different initial vertical load levels at $1.45 \mathrm{D}$

Figure 11. Swipe tests against the fitted surface in the $V Q$ plane

Figure 12. Experimental data against the fitted yield surface in the normalised $H M$ plane

Figure 13. Comparison of yield surface shape in the normalised $V H(M=0)$ and $V M(H=0)$ planes

Figure 14. Variation of $h_{0}$ and $m_{0}$ with embedment depth

Figure 15. Variation of eccentricity with embedment depth

Figure 16. Plastic flow in the $H M$ plane

Figure 17. Load paths and example yield surfaces of radial displacement tests

Figure 18. Plastic flow indicated by radial displacement tests

Figure 19. Simulation of a pure vertical penetration-extraction test

Figure 20. Simulation of swipe test PCS2

Figure 21. Simulation of swipe test PTS2

Figure 22. Simulation of radial displacement test R6 